\title{
Housing and Debt over the Life Cycle and over the Business Cycle*
}

\author{
Matteo Iacoviello ${ }^{\dagger}$ \\ Federal Reserve Board
}

\author{
Marina Pavan $\ddagger$ \\ Universitat Jaume I \& LEE
}

September 19, 2011

\begin{abstract}
We study housing and debt in a quantitative general equilibrium model. In the cross-section, the model matches the wealth distribution, the age profiles of homeownership and mortgage debt, and the frequency of housing adjustment. In the time-series, the model matches the procyclicality and volatility of housing investment, and the procyclicality of mortgage debt. We use the model to conduct two experiments. First, we investigate the consequences of higher individual income risk and lower downpayments, and find that these two changes can explain, in the model and in the data, the reduced volatility of housing investment, the reduced procyclicality of mortgage debt, and a small fraction of the reduced volatility of GDP. Second, we use the model to look at the behavior of housing investment and mortgage debt in an experiment that mimics the Great Recession: we find that countercyclical financial conditions can account for large drops in housing activity and mortgage debt when the economy is hit by large negative shocks.

Keywords: Housing, Housing Investment, Mortgage Debt, Life-cycle Models, Income Risk, Homeownership, Precautionary Savings, Borrowing Constraints.

JeL Codes: E22, E32, E44, E51, D92, R21.

*We thank Massimo Giovannini and Joachim Goeschel for their invaluable research assistance. We thank Chris Carroll, Kalin Nikolov, Dirk Krueger, Makoto Nakajima, as well as various seminar and conference participants for helpful comments on various drafts of this paper. Pavan aknowledges financial support from the Spanish Ministry of Education (Programa de Movilidad de Jovenes Doctores Extranjeros). Supplementary material is available at the website https://www2.bc.edu/ iacoviel/.

${ }^{\dagger}$ Matteo Iacoviello, Division of International Finance, Federal Reserve Board, 20th and C St. NW, Washington, DC 20551. Email: matteo.iacoviello@frb.gov.

‡Marina Pavan, Universitat Jaume I \& LEE, Castellón, Spain. E-mail: pavan@eco.uji.es.
\end{abstract}




\section{Introduction}

This paper studies the business cycle and the life-cycle properties of housing investment and household mortgage debt in a quantitative general equilibrium model. To this end, we modify a life-cycle model with uninsurable individual income risk to allow for aggregate uncertainty and for an explicit treatment of housing. We introduce housing by modeling its role as collateral, its lumpiness, and the choice of renting versus owning; these features have, to a large extent, eluded existing business cycle models of housing.

At the cross-sectional level, our model accurately reproduces the U.S. wealth distribution, and replicates the life-cycle profiles of housing and nonhousing wealth. The young, the old and the poor are renters and hold few assets; the middle-aged and the wealth-rich are homeowners. For a typical household, the asset portfolio consists of a house and a large mortgage. The model also reproduces frequency and size of individual housing adjustment: because of nonconvex adjustment costs, homeowners change house size infrequently but in large amounts when they do so; renters change house size often, but in smaller amounts. Over the business cycle, the model replicates two empirical characteristics of housing investment: its procyclicality and its high volatility. In addition, the model matches the procyclical behavior of household mortgage debt. To our knowledge, no previous model with rigorous micro-foundations for housing demand has reproduced these regularities in general equilibrium.

We use the model to look at the role of the housing market in two events of the recent U.S. macroeconomic history: the Great Moderation and the Great Recession.

Debt and Housing in the Great Moderation. We study how higher household income risk and lower downpayments affect the sensitivity of debt and housing to macroeconomic shocks. Higher risk and the reduction in downpayments occurred around the 1980s, around the beginning of the Great Moderation, ${ }^{1}$ and are potentially important determinants of housing demand and housing tenure: higher risk should make individuals reluctant to buy large items that are costly

\footnotetext{
${ }^{1}$ Campbell and Hercowitz (2005) and Gerardi, Rosen and Willen (2010) discuss the role of financial reforms, and Dynan, Elmendorf and Sichel (2007) discuss the evolution of household income volatility.
} 
to sell in bad times; lower downpayments should encourage and smooth housing demand. Their role could be relevant given two observations on the post-1980s period (see Figure 1 and Table 1). First, the volatility of housing investment has fallen more than proportionally relative to GDP; second, the correlations between mortgage debt and GDP and mortgage debt and aggregate consumption have roughly halved, from 0.78 to 0.43 and from 0.72 to 0.37 respectively. $^{2}$ In line with the data, we find that lower downpayments and larger idiosyncratic risk reduce the volatility of housing investment, and reduce the correlation between mortgage debt and economic activity. Lower downpayments provide a cushion to smooth housing demand; increase homeownership rates, raising the number of people who do not change their housing consumption over the cycle (relative to an economy with a large number of renters who can become first-time buyers); lead to higher debt, creating a mechanism that weakens the correlation between output and hours. Higher idiosyncratic risk makes wealth-poor individuals more cautious: these individuals adjust consumption, hours, and housing by smaller amounts in response to aggregate shocks. This mechanism is pronounced for housing purchases, since a house is a large item that is costly to purchase and sell; and is reinforced by low downpayments, since low downpayments allow people to borrow more, increasing the utility cost of buying and selling when net worth is lower. Together, lower downpayments and higher risk can explain about 15 percent of the reduction in the variance of GDP, 60 percent of the reduction in the variance of housing investment, and the decline in the correlation between debt and GDP.

Debt and Housing in the Great Recession. During the 2007-2009 period, changes in financial conditions are likely to have made the recession worse. In particular, the housing market appears to have been held back - more than other sectors - by tighter credit conditions and higher borrowing costs. In hindsight, it looks like housing did not stabilize the economy during the recession. We use the model to determine the extent to which housing can smooth regular business cycle shocks but amplify extremely negative ones, by defining "Normal Recessions" as periods of low aggregate productivity, and "Great Recessions" periods of low aggregate produc-

\footnotetext{
${ }^{2}$ If one excludes the 2008-2010 period from the time-series, the decline in the volatility of housing investment and the decline in the correlation between debt and GDP are slightly larger.
} 
tivity coupled with tight credit conditions. When we do so, we find an interesting nonlinearity: higher risk and lower downpayments can make housing and debt more stable in response to small positive and negative shocks (as in the Great Moderation), but can make it more fragile in response to large negative shocks (as in the Great Recession).

Previous Literature. Two strands of literature study the role of housing in the macroeconomy. On the one hand, business cycle models with housing - Greenwood and Hercowitz (1991), Gomme, Kydland and Rupert (2001), Davis and Heathcote (2005), Fisher (2007) and Iacoviello and Neri (2010) - match housing investment well, but abstract from a detailed modeling of the microfoundations of housing demand; these models feature no wealth heterogeneity, no distinction between owning and renting, and unrealistic transaction costs. On the other hand, incomplete markets models with housing - Gervais (2002), Fernandez-Villaverde and Krueger (2004), Chambers, Garriga and Schlagenhauf (2009), and Díaz and Luengo-Prado (2010) - have a rich treatment of the microfoundations of housing demand, but ignore aggregate shocks: however, because these papers model individual heterogeneity, they are better suited to study issues such as debt, risk, and wealth distribution.

Our model combines both strands of literature. Others have also done so, albeit with a different focus. Silos (2007) studies the link between aggregate shocks and housing choice, but does not model the own/rent decision and assumes convex costs for housing adjustment. ${ }^{3}$ Fisher and Gervais (2007) find that the decline in housing investment volatility is driven by a change in the demographics of the population together with an increase in the cross-sectional variance of earnings. Their approach sidesteps general equilibrium considerations. Kiyotaki, Michaelides and Nikolov (2011) use a stylized life-cycle model of housing tenure to study the interaction between borrowing constraints, housing prices, and economic activity. Favilukis, Ludvigson and Van Nieuwerburgh (2009) use a two-sector RBC model with housing that also considers the interaction between borrowing constraints and aggregate activity, but address a different set of

\footnotetext{
${ }^{3}$ Under convex costs, housing adjustment takes the form of a series of small adjustments over a number of periods. Under our specification, the homeowner's housing stock follows an $(S, s)$ rule, remaining unchanged over a long period and ultimately changing by a potentially large amount. See Carroll and Dunn (1997) for an early partial equilibrium model with $(S, s)$ behavior for housing.
} 
questions than we do. Finally, Campbell and Hercowitz (2005) study the impact of financial innovation on macroeconomic volatility in a model with two household types. In their model, looser collateral constraints weaken the connection between constrained households' housing investment, debt accumulation and labor supply through a mechanism that shares some features with ours; however, their model does not study the interaction between life cycle, risk and housing demand, which are important elements of our story.

\section{The Model}

Our economy is a version of the stochastic growth model with overlapping generations of heterogeneous households, extended to allow for housing investment, collateralized debt and a housing rental market. Aggregate uncertainty is introduced in the form of a shock to total factor productivity. Individuals live at most $T$ periods and work until age $\widetilde{T}<T$. Their labor endowment depends on a deterministic age-specific productivity and a stochastic component. After retirement, people receive a pension. Each period, the probability of surviving from age $a$ to $a+1$ is $\chi_{a+1}$. Each period a generation is born of the same measure of dead agents, so that the total population, which we normalize to 1 , is constant. When an agent dies, he is replaced by a descendant who inherits his assets.

At each point in time, agents differ by their age and productivity; moreover, we assume that agents differ in their degree of impatience. We do so for two reasons: first, a large literature (see Guvenen, 2011) suggests that preference heterogeneity may be an important source of wealth inequality. For example, Venti and Wise (2001) study wealth inequality at the onset of retirement among households with similar lifetime earnings and conclude that the dispersion must be attributed to differences in the amount that households choose to save. ${ }^{4}$ Second, we want a model that generates average debt and wealth dispersion as in the data, and a model with discount factor heterogeneity works remarkably well in this regard (our robustness analysis discusses the properties of the model with a single discount factor).

\footnotetext{
4 Krusell and Smith (1998) explore a heterogeneous-agents setting with discount rate heterogeneity which replicates key features of the data on the distribution of wealth.
} 
Household Preferences and Endowments. Households receive utility from consumption $c$, leisure $\bar{l}-l$ (where $\bar{l}$ is the time endowment), and service flows $s$ from housing, which are proportional to the housing stock owned or rented. The momentary utility function is:

$$
u(c, s, \bar{l}-l)=\log c+j \log (\theta s)+\tau \log (\bar{l}-l)
$$

Above, $\theta=1$ if $s=h>0$ (the individual owns), while $\theta<1$ if $h=0$ (the individual rents). The assumption for $\theta$ implies that a household experiences a utility gain when transitioning from renting to owning, as in Rosen (1985) and Poterba (1992). We also assume that homeowners need to hold a minimum size house $\underline{h}$, and that rental units may come in smaller sizes than houses, allowing renters to consume a smaller amount of housing services, as in Gervais (2002). The log specification over consumption and housing services follows Davis and Ortalo-Magné (2011) who find that, over time and across cities, the expenditure share on housing is constant.

Time supplied in the labor market is paid at the wage $w_{t}$. The productivity endowment of an agent at age $a$ is given by $\eta_{a} z$, where $\eta_{a}$ is a deterministic age-specific component and $z$ is a shock to the efficiency units of labor, $z \in \widetilde{Z} \equiv\left\{z^{1}, \ldots, z^{n}\right\}$. The shock follows a Markov process with transition matrix $\pi_{z, z^{\prime}}=\operatorname{Pr}\left(z_{t+1}=z^{\prime} \mid z_{t}=z\right)$ and stationary distribution $\Pi(z)=\operatorname{Pr}\left(z_{t}=z\right)$. The total amount of labor efficiency units $\sum_{i=1}^{n} z^{i} \Pi\left(z^{i}\right)$ and of age-specific productivity values $\sum_{a=1}^{\widetilde{T}} \eta_{a} \Pi_{a}$ are constant and normalized to one. From $\widetilde{T}+1$ onwards labor efficiency is zero $(z=0)$ and agents live off their pension $P$ and their accumulated wealth. Pensions are fully financed through the government's revenues from a lump-sum tax $\Gamma$ paid by workers. ${ }^{5}$ Total net income at age $a$ in period $t$ is denoted by $y_{a t}$. Then:

$$
y_{a t}=w_{t} \eta_{a} z_{t} l_{t}-\Gamma \text { if } a \leq \widetilde{T} ; y_{a t}=P \text { if } a>\widetilde{T}
$$

Households start their life with endowments $b_{0}$ and $h_{0}$, the accidental bequests left by a dead agent. They can trade a one-period bond $b$ which pays a gross interest rate of $R_{t}$. Positive amounts of this bond denote a debt position. ${ }^{6}$ Households cannot borrow more than a fraction

\footnotetext{
${ }^{5}$ We crudely assume that the pension is the same for everyone. Allowing pensions to mimic something that looks like the actual Social Security system in the U.S. would make our model computationally intractable, since it would enlarge the state variables in the household problem to encompass their entire income history.

${ }^{6}$ We refer to $b$ as financial liabilities, and to $-b$ as financial assets. Because bonds are claims on aggregate capital, their return varies with the aggregate state.
} 
$m_{H}<1$ of their housing stock and a fraction $m_{Y}$ of their expected earnings:

$$
b_{t} \leq \min \left\{m_{H} h_{t}, m_{Y} \Re_{t}\left(y_{a t} ; R_{t}, w_{t}\right)\right\} .
$$

Above, $\Re_{t}\left(\bar{y}_{a t} ; R_{t}, w_{t}\right)=\bar{y}_{a t}+\sum_{s=a+1}^{T} \frac{E_{t}\left(y_{s} \mid \bar{y}_{a t} ; w_{t}\right)}{\left(R_{t}\right)^{s-a}}$ approximates the present discounted value of lifetime labor earnings and pension. ${ }^{7}$ The motivation for this borrowing constraint is realism: we want to study mortgage debt and we want to have a constraint which prevents the elderly from borrowing too much late in life (when the present discounted value of earnings is low), as in the data. The constraint is also consistent with typical lending criteria in the mortgage market that take into account minimum downpayments, ratios of debt payments to income, current and expected future employment conditions. ${ }^{8}$ Finally, we assume that an owner incurs a transaction cost whenever he adjusts the housing stock: $\Psi\left(h_{t}, h_{t-1}\right)=\psi h_{t-1}$ if $\left|h_{t}-h_{t-1}\right|>0$. This assumption captures common practices in the housing market that require, for instance, fees paid to realtors to be equal to a fraction of the value of the house being sold. Summing up, households maximize expected lifetime utility:

$$
E_{1}\left(\sum_{a=1}^{T} \beta_{i}^{a-1} \lambda_{a}\left(\prod_{\tau=1}^{a-1} \chi_{\tau+1}\right) u\left(c_{a}, s_{a}, \bar{l}-l_{a}\right)\right)
$$

where $E_{1}$ denotes expectations at age $a=1, \lambda_{a}$ is a deterministic preference shifter that mimics changes in household size, and $\beta_{i}$ is a household-specific discount factor. In the calibration, we assume that households are born either impatient (low $\beta$ ) or patient (high $\beta$ ).

Financial Sector and Housing Rental Market. A competitive financial sector collects deposits from households who save, lends to firms and households who borrow, and buys capital to be rented in the same period to tenants. The financial sector can convert the final good into housing and capital at no cost. This assumption ensures that the consumption prices of housing and capital are constant. Let $p_{t}$ be the price of one unit of rental services. Then a no-arbitrage condition holds such that the net revenue from lending one unit of financial capital must equal

\footnotetext{
${ }^{7}$ To compute $\Re_{t}$, we fix interest and wages at current values. To compute $\bar{y}_{a t}$, we assume $l_{t}=\bar{l}$ for $t \leq \widetilde{T}$.

${ }^{8}$ In the United States, lending institutions typically send a "Verification of Employment" (VOE) form to the borrower's employer to determine start date of employment, current and previous salary, and the probability of continued employment among other things.
} 
the net revenue from renting one unit of housing capital,

$$
p_{t}=1-E_{t}\left(\left(1-\delta_{H}\right) / R_{t+1}\right)
$$

at any $t$, where $\delta_{H}$ is the depreciation rate of the housing stock. ${ }^{9}$

Production. The goods market is competitive and characterized by constant returns to scale, so that we consider a single representative firm. Output is produced according to

$$
Y_{t}=A K_{t-1}^{\alpha} L_{t}^{1-\alpha},
$$

where $K$ and $L$ are total capital and labor input; $\alpha$ is the capital share, and $A \in \widetilde{A} \equiv\left\{A^{1}, . ., A^{n_{A}}\right\}$ is a shock to total factor productivity. This shock follows a Markov process with transition matrix $\pi_{A, A^{\prime}}=\operatorname{Pr}\left(A_{t+1}=A^{\prime} \mid A_{t}=A\right)$. The aggregate feasibility constraint requires that production of the good $Y_{t}$ equals the sum of aggregate consumption $C_{t}$, investment in the stock of aggregate capital $K_{t}$, investment in the stock of aggregate housing $H_{t}=H_{t}^{o}+H_{t}^{r}$, and total transaction costs incurred by homeowners for changing housing stock, denoted by $\Omega_{t}$ :

$$
C_{t}+H_{t}-\left(1-\delta_{H}\right) H_{t-1}+\Omega_{t}+K_{t}-\left(1-\delta_{K}\right) K_{t-1}=Y_{t},
$$

with $\delta_{H}$ and $\delta_{K}$ denoting the depreciation rates of housing and capital, respectively.

The Household Problem and Equilibrium. Denote with $\Phi_{t} \equiv \Phi_{t}\left(z_{t}, b_{t-1}, h_{t-1} ; \beta, a\right)$ the distribution of households over earnings shocks, asset holdings, housing wealth, discount factors and ages in period $t$. Without aggregate uncertainty, the economy would be in a stationary equilibrium, with an invariant distribution $\Phi$ and constant prices. Given aggregate volatility, this distribution will change over time. When solving their dynamic optimization problem, agents need to predict future wages and interest rates. Both variables depend on future productivity and aggregate capital-labor ratio, which in turn are determined by the overall distribution of

\footnotetext{
${ }^{9}$ One can interpret the marginal cost of one house to be 1 for the financial sector, since loanable funds can be converted into housing costlessly; and the marginal benefit to be the sum of the current rental income, $p_{t}$, plus expected return next period, $E_{t}\left(\left(1-\delta_{H}\right) / R_{t+1}\right)$, where $R_{t}$ is the opportunity cost of funds for the financial sector. Equating costs and benefits yields equation (5).
} 
individual states. As a consequence, the distribution $\Phi_{t}-$ and its law of motion - is one of the aggregate state variables that agents need to know in order to make their decisions (together with total factor productivity). This distribution is an infinite-dimensional object, and its law of motion maps an infinite-dimensional space onto itself, which imposes a crucial complication for the solution of the model economy. To circumvent this problem, we adopt the strategy of Krusell and Smith (1998) and let agents use one moment of the distribution $\Phi$ - the aggregate capital stock $K$ - in order to forecast future prices. As documented in Appendix A, using one moment only allows us to obtain a fairly precise forecast, as measured by the $R^{2}$ of the forecasting equations, which are between 0.99 and $1 .^{10}$

We write the household optimization problem recursively. The individual states are productivity $z_{t}$, debt $b_{t-1}$, and housing wealth $h_{t-1}$. We assume that agents observe beginning of period capital $K_{t-1}$ and approximate the evolution of aggregate capital and labor with linear functions that depend on the aggregate shock $A_{t}$. Denote $x_{t} \equiv\left(z_{t}, b_{t-1}, h_{t-1}, A_{t}, K_{t-1}\right)$ the vector of individual and aggregate states. The dynamic problem of an age $a$ household is:

$$
V_{a}\left(x_{t} ; \beta_{i}\right)=\max _{I^{h} \in\{0,1\}}\left\{I^{h} V_{a}^{h}\left(x_{t} ; \beta_{i}\right)+\left(1-I^{h}\right) V_{a}^{r}\left(x_{t} ; \beta_{i}\right)\right\}
$$

where $V_{a}^{h}$ and $V_{a}^{r}$ are the value functions if the agent owns and rents, respectively, and $I^{h}=1$ corresponds to the decision to own. The value of being a homeowner solves:

$$
\begin{gathered}
V_{a}^{h}\left(x_{t} ; \beta_{i}\right)=\max _{c_{t}, b_{t}, h_{t}, l_{t}}\left\{\lambda_{a} u\left(c_{t}, h_{t}, \bar{l}-l_{t}\right)+\beta_{i} \chi_{a+1} \sum_{z^{\prime}, A} \pi_{A, A^{\prime}} \pi_{z, z^{\prime}} V_{a+1}\left(x_{t+1} ; \beta_{i}\right)\right\} \\
\text { s.t. } \quad c_{t}+h_{t}+\Psi\left(h_{t}, h_{t-1}\right)=y_{a t}+b_{t}-R_{t} b_{t-1}+\left(1-\delta_{H}\right) h_{t-1}, \\
b_{t} \leq \min \left\{m_{H} h_{t}, m_{Y} \Re_{t}\right\}, c_{t} \geqslant 0, l_{t} \in(0, \bar{l}), \\
K_{t}=\digamma^{K}\left(K_{t-1}, A_{t}\right), L_{t}=\digamma^{L}\left(K_{t-1}, A_{t}\right) .
\end{gathered}
$$

Here $\digamma^{K}$ and $\digamma^{L}$ are linear functions in $K_{t-1}$, whose parameters depend on the $A_{t}$. They denote

\footnotetext{
${ }^{10}$ We have examined the robustness of our results by letting agents use both the aggregate capital stock $K$ and the housing stock $H$ in forecasting future prices, with nearly identical results, but at a higher computational cost. It is possible that higher moments of the wealth distribution could be both relevant in predicting future prices and yield different aggregate dynamics, so that our decision rules would describe a bounded rationality equilibrium, rather than a good approximation to the rational expectations equilibrium. Yet the evidence that adding $H$ to the set of the state variables does not change aggregate dynamics leads us to be skeptical of this interpretation. See Young (2010) for an insightful discussion of these issues.
} 
the law of motion of the aggregate state, which agents take as given.

The value of renting a house is determined by solving the problem:

$$
\begin{gathered}
V_{a}^{r}\left(x_{t} ; \beta_{i}\right)=\max _{c_{t}, b_{t}, s_{t}, l_{t}}\left\{\lambda_{a} u\left(c_{t}, s_{t}, \bar{l}-l_{t}\right)+\beta_{i} \chi_{a+1} \sum_{z^{\prime}, A}, \pi_{A, A^{\prime}} \pi_{z, z^{\prime}} V_{a+1}\left(x_{t+1} ; \beta_{i}\right)\right\} \\
\text { s.t. } \quad c_{t}+p_{t} s_{t}+\Psi\left(0, h_{t-1}\right)=y_{a t}+b_{t}-R_{t} b_{t-1}+\left(1-\delta_{H}\right) h_{t-1}, \\
b_{t} \leq 0, c_{t}>0, l_{t} \in(0, \bar{l}), h_{t}=0, \\
K_{t}=\digamma^{K}\left(K_{t-1}, A_{t}\right), L_{t}=\digamma^{L}\left(K_{t-1}, A_{t}\right) .
\end{gathered}
$$

At the agent's last age, $V_{T+1}\left(x_{T+1} ; \beta\right)=0$ for any $\left(x_{T+1} ; \beta\right)$.

We are now ready to define the equilibrium for this economy.

Definition 2.1. A recursive competitive equilibrium consists of value functions $\left\{V_{a}\left(x_{t} ; \beta\right)\right\}_{a=1, . ., T ; t=1, . ., \infty}$ policy functions $\left\{I_{a}^{h}\left(x_{t} ; \beta\right), h_{a}\left(x_{t} ; \beta\right), s_{a}\left(x_{t} ; \beta\right), b_{a}\left(x_{t} ; \beta\right), c_{a}\left(x_{t} ; \beta\right), l_{a}\left(x_{t} ; \beta\right)\right\}$ for each $\beta$, age and period $t$, prices $R_{t}, w_{t}$ and $p_{t}$, aggregate quantities $K_{t}, L_{t}, H_{t}^{o}$ and $H_{t}^{r}$ for each $t$, taxes $\Gamma$ and pensions $P$, and laws of motion $\digamma^{K}$ and $\digamma^{L}$ such that at any $t$ :

Agents optimize: Given $R_{t}, w_{t}, p_{t}$, and the laws of motion $\digamma^{K}$ and $\digamma^{L}$, the value functions solve the individual's problem, with the corresponding policy functions.

Factor prices and rental prices satisfy:

$$
\begin{gathered}
R_{t}-1+\delta_{K}=\alpha A_{t}\left(K_{t-1} / L_{t}\right)^{\alpha-1}, \\
w_{t}=(1-\alpha) A_{t}\left(K_{t-1} / L_{t}\right)^{\alpha} \\
p_{t}=1-E_{t}\left(\left(1-\delta_{H}\right) / R_{t+1}\right) .
\end{gathered}
$$

Markets clear:

$$
\begin{gathered}
L_{t}=\int l_{a}\left(x_{t} ; \beta\right) \eta_{a} z_{t} d \Phi_{t} \text { (labor market) } \\
C_{t}+H_{t}-\left(1-\delta_{H}\right) H_{t-1}+\Omega_{t}+K_{t}-\left(1-\delta_{K}\right) K_{t-1}=Y_{t} \text { (goods market) }
\end{gathered}
$$

where $H_{t}$ and $\Omega_{t}$ are defined as:

$$
\begin{gathered}
H_{t}=H_{t}^{o}+H_{t}^{r}=\int I_{a}^{h}\left(x_{t} ; \beta\right) h_{a}\left(x_{t} ; \beta\right) d \Phi_{t}+\int\left(1-I_{a}^{h}\left(x_{t} ; \beta\right)\right) s_{a}\left(x_{t} ; \beta\right) d \Phi_{t}, \\
\Omega_{t}=\int \Psi\left(h_{a}\left(x_{t} ; \beta\right), h_{t-1}\right) d \Phi_{t} .
\end{gathered}
$$


The government budget is balanced:

$$
\sum_{a=1}^{\widetilde{T}} \Pi_{a} \Gamma=\sum_{a=\widetilde{T}+1}^{T} \Pi_{a} P
$$

The laws of motion for the aggregate capital and aggregate labor are given by

$$
K_{t}=\digamma^{K}\left(K_{t-1}, A_{t}\right), L_{t}=\digamma^{L}\left(K_{t-1}, A_{t}\right) .
$$

Appendix A provides the details on our computational strategy.

\section{Calibration}

Our calibration is summarized in Table 2. One period is a year. Agents enter the model at age 21 , retire at age 65 , and die no later than age 90 . The survival probabilities correspond to the survival probabilities for men aged 21-90 from the U.S. Decennial Life Tables for 1989-1991. Each period, the measure of those who are born is equal to the measure of those who die. The age polynomial $\lambda_{a}$, which captures the effect of demographic variables in the utility function, is taken from Cagetti (2003) and approximated using a fourth-order polynomial (see Figure 2). After normalizing the household size to 1 at age 21, the household size peaks at 2.5 at age 40, and declines thereafter.

We take the deterministic profile of efficiency units of labor for males aged 21-65 from Hansen (1993) and approximate it using a quadratic polynomial (see Figure 2). Upon retirement, an agent receives a pension equal to 40 percent of the average labor income. ${ }^{11}$ The idiosyncratic shock to labor productivity is specified as:

$$
\log z_{t}=\rho_{Z} \log z_{t-1}+\sigma_{Z}\left(1-\rho_{Z}^{2}\right)^{1 / 2} \varepsilon_{t}, \quad \varepsilon_{t} \sim \operatorname{Normal}(0,1),
$$

which we approximate with a three-state Markov process following Tauchen (1986). There is a vast literature on the nature and specification of a parsimonious yet empirically plausible income process: the bulk of the studies (see Guvenen, 2011) look at earnings (rather than wages)

\footnotetext{
${ }^{11}$ Queisser and Whitehouse (2005) report that average pensions for males in the United States are 40 percent of the economy-wide average earnings.
} 
and estimate persistence coefficients ranging from 0.7 to 0.95 . Exception are Floden and Lindé (2001), who use PSID data to estimate an AR(1) process for wages similar to ours and find an autocorrelation coefficient of 0.91 ; and Card (1991), who finds an AR(1) coefficient of 0.89. Based on this evidence, we set $\rho_{Z}=0.9$, and conduct robustness analysis in Section 8 , based on evidence from other studies that we review in Appendix B. The standard deviation of the labor productivity process is set at $\sigma_{Z}=0.30$ (see Appendix B). Later, we increase $\sigma_{Z}$ to 0.45 to capture the increased earnings volatility of the 1990s, and to study the consequences for macroeconomic aggregates of increased risk at the household level, as emphasized by Moffitt and Gottschalk (2008) and Dynan, Elmendorf and Sichel (2007).

We assume that there are two classes of households, a "patient" group with a discount factor of 0.999 (one third of the population) and an "impatient" group with a discount factor of 0.941 (two thirds of the population). The high discount factor pins the average real interest rate down to 3 percent. The low discount factor is in the range of estimates in the literature (see, for instance, Hendricks, 2007). The gap between discount rates and the relative population shares deliver a Gini coefficient for wealth around 0.75, close to the data. In Section 8 we discuss the properties of the model when we assume that all people have identical discount rates. We set $\tau=1.65$ and the endowment of time $\bar{l}=2.65$; these parameters imply that time spent working is 40 percent of the agents' time.

We set the weight on housing in utility at $j=0.15$, and the depreciation rate for housing $\delta_{H}=0.05$. These parameters yield average housing investment to private output ratios around 7 percent, and a ratio of the housing stock to output 1.4. These values are in accordance with the National Income and Product Accounts and the Fixed Assets Tables. ${ }^{12}$ Finally, the housing transaction cost is set at $\psi=5 \%$ based on estimates from the National Association of Realtors

\footnotetext{
12 The NIPA Fixed Asset Tables indicate depreciation rates for housing ranging from 1.2 to 4.5 percent, depending on the type of structure and its use (see Fraumeni, 1997). We choose a slightly higher value because we want to account for unmeasured labor time that is used to repair, renovate, or maintain or improve the quality of housing at a given location (Peek and Wilcox, 1991); because higher values are typically considered in the existing literature, especially when housing is broadly interpreted to include consumer durables (Chambers, Garriga and Schlagenhauf, 2009, Gervais 2002, and Díaz and José Luengo-Prado, 2010); and because a higher depreciation rate ( 5 percent instead of 2 percent, say) reduces the extent to which aggregate housing tends to decrease on impact following a positive aggregate technology shock in a model with two capital goods.
} 
(2005). ${ }^{13}$ Section 8 conducts robustness analysis for alternative values of $\psi$ and $\delta_{H}$.

We set $\alpha=0.26$ and $\delta_{K}=0.09$. These values yield an average capital to output ratios around 2.2 and average business investment to output ratios around 20 percent. The aggregate shock is calibrated to match the standard deviation of output in the data for the period 19521982. We use a Markov-chain specification with seven states to match the following first-order autoregression for the log of total factor productivity:

$$
\log A_{t}=\rho_{A} \log A_{t-1}+\sigma_{A}\left(1-\rho_{A}^{2}\right)^{1 / 2} \varepsilon_{t}, \quad \varepsilon_{t} \sim \operatorname{Normal}(0,1)
$$

We set $\rho_{A}=0.925$ and $\sigma_{A}=0.0148$. After rounding, the first number mimics a quarterly autocorrelation rate of productivity of 0.979, as in King and Rebelo (1999). The second number is chosen to match the standard deviation of model output to its data counterpart.

Our baseline calibration sets the maximum loan-to-value ratio $m_{H}$ at 0.75 . We increase $m_{H}$ to 0.85 in the calibration for the late period. The value of $m_{Y}$ is set at 0.25 in the baseline and raised to 0.5 in the late period: with these numbers, the income constraint only binds late in life, preventing old homeowners from borrowing. Aside from this, our choice for $m_{Y}$ is of small importance for the model dynamics. Lastly, the minimum-size house available for purchase $(\underline{h})$ costs 1.5 times the average annual pre-tax household income. ${ }^{14}$ Together with the minimum house size, the parameter that has a large impact on homeownership is the utility penalty for renting $(\theta)$. We set $\theta=0.838$ to obtain a homeownership rate of 64 percent, as in the data for the period 1952-1982.

\section{Steady-State Results}

Household Behavior. At each stage in the life, the household chooses consumption, saving, hours, and housing investment by taking into account current and expected income, and liquid

\footnotetext{
13 The National Association of Realtors estimates that average commission rates (excluding houses sold without brokers, which account for about 10 to 25 percent of existing home sales, according to media reports, reports of the National Association of Realtors, and academic studies) range from 4.3 to 5.4 percent, based on 2004 data documenting a $\$ 65$ billion brokerage industry and an existing home sales volume of $\$ 1.35$ trillion.

14 According to the 2009 American Housing Survey, only 20 percent of total owner-occupied units have a ratio to current income less than 1.5.
} 
assets and housing position at the beginning of the period. Here, we mostly focus on housing decisions, since other features of the model are in line with existing models of life-cycle consumption and saving behavior. We defer illustrating labor supply behavior to the next section, when we discuss the model dynamics in response to aggregate shocks.

It is simple to characterize the behavior of agents depending on whether they start the period as renters or homeowners. For renters, the housing choice is as follows: given the initial state, there is a threshold amount of liquid assets ( $-b$ in our notation) such that, if assets exceed the threshold, renters become homeowners. Also, the larger initial liquid assets are, the less likely a household is to borrow to finance its housing purchase.

Homeowners can stay put, increase house size, downsize or switch to renting. Figure 3 plots optimal housing choice as a function of initial house size and liquid wealth. ${ }^{15}$ The downward sloping line plots the borrowing constraint that restricts debt from exceeding a fraction $m_{H}$ of its housing stock. As the figure illustrates, larger liquid assets trigger larger housing. In addition, buying and selling costs create a region of inaction where the household keeps its housing constant. If liquid wealth falls, the household either downsizes or switches to renting. One feature of the model is that, for a household with very small liquid assets, the housing tenure decision is non-monotonic in the initial level of housing wealth. Consider, for instance, a homeowner with liquid assets equal to about one. If the initial house size is small, the homeowner does not change house size, since, given the small amount of assets, the house size is closer to its optimal choice. If the initial house is medium-sized, the homeowner pays the adjustment cost and, because of his low liquid assets, switches to renting. If the initial house size is large, it is optimal to downsize, and to buy a smaller house.

Life-Cycle Profiles. Figure 4 plots a typical individual life-cycle profile in our model. We choose an agent with a low discount factor since the behavior of an agent with low assets and often close to the borrowing constraint best illustrates the main workings of the model. The agent starts life as a renter, with little assets and low income. At the age of 22 , he is hit by a

\footnotetext{
15 The figure is plotted for a patient agent who is entering retirement ( 65 years old), when aggregate productivity and the capital-labor ratio are equal to their average value.
} 
positive income shock, saves in order to afford the downpayment and buys a house a year after. Prior to buying a house, the individual works more: the positive income shock raises the incentive to work; and such incentive is reinforced by need to set resources aside for the downpayment. Following a series of above average income shocks beginning at the age of 32 , the agent buys a larger house at the age of 39. This time, in order to afford the larger house, the individual is much closer to his borrowing limit. In particular, while he owns and is close to the borrowing limit, hours move in the opposite direction to wage shocks, rising in bad times (age 42), falling in good times (age 45): such mechanism is explained in detail in the next Section. As retirement approaches, the agent pays back part of the mortgage, and works more. After retirement, at the age of 70, he switches to a small rental unit, before dying at the age of 90 .

One dimension where it is illustrative to compare the model with the data is the frequency of housing adjustment for homeowners. ${ }^{16}$ Using the 1993 Survey of Income and Program Participation, Hansen (1998) reports that the median homeowner stays in the same house for about 8 years. Anily, Hornik, and Israeli (1999) estimate that the average homeowner lives in the same residence for 13 years. The corresponding number for our model is 15 years. ${ }^{17}$

Figure 5 compares the age profiles of housing, debt and homeownership with their empirical counterparts. Like the data, the model is able to capture the hump-shaped profiles of these variables. There are two discrepancies: as for mortgage debt, the model slightly underpredicts debt early in life, and overpredicts debt later in life. The model also underpredicts homeownership later in life: we believe that, late in life, the absence of any bequest motive and the need to finance consumption expenditure by selling the house more than offset the adjustment costs, thus generating a sharp decline in homeownership.

The Wealth Distribution. Our model reproduces the U.S. wealth distribution quite well. The Lorenz curves for the U.S. economy and for our model economy are reported in figure 6 .

\footnotetext{
16 In the model, renters change their housing position every period, since they face no cost in doing so. This assumption is in line with the data, that show that on average renters move about every two years.

17 We are aware, of course, of the difficulty in comparing the model with the data along this dimension: in the data, 15 percent of the moves are associated with a move to a different state, and 35 percent of the moves are associated with a move to a different county. Most of these moves are probably "moving shocks" rather than movements along the housing ladder.
} 
The Gini coefficient for wealth in the model is 0.73 , and is about the same as in the data (equal to 0.79). Our model still underpredicts wealth inequality at the very top of the distribution, both for housing and for total wealth. However, the model does well at matching the fraction of wealth (both housing wealth and overall wealth) held by the poorest 40 percent of the U.S. population, which has essentially no assets and no debt. Instead, a model without preference heterogeneity would do much worse: in Section 8 we show that the Gini coefficient for wealth in the model with a single discount factor is 0.53 , much lower than in the data.

In the same vein, the model predicts a mortgage debt to GDP ratio that is roughly in line with the data (0.31 vs. 0.34$)$ and a fraction of liquidity constrained agents that is consistent with the available empirical estimates. Following Hall (2011), we take a model agent to be liquidityconstrained if the holdings of net liquid assets are less than two months $(16.67 \%$ on an annual basis) of income. ${ }^{18}$ Using this definition, $45 \%$ of households are liquidity constrained. ${ }^{19}$ Jappelli (1990) estimates the share of liquidity constrained individuals to be $20 \%$. Studies that have combined self-reported measures of credit constraints from the Survey of Consumer Finances with indirect inference from other datasets (such as the PSID), have typically found that 20 percent is more likely to be a lower bound. For instance, using evidence on the response of spending to changes in credit card limits, Gross and Souleles (2002) argue that the overall fraction of potentially constrained households is over two thirds.

\section{Business Cycle Results}

We now illustrate the propagation mechanism of aggregate shocks. There are two aspects of heterogeneity that matter for aggregate dynamics: one is exogenous, and reflects the assumption that individuals have different abilities, planning horizons, and utility weights. Because other papers have studied these features in life-cycle models with aggregate shocks, we do not

\footnotetext{
${ }^{18}$ Liquid assets are defined as lqas $\equiv m_{H} h^{\prime}-b^{\prime}$. According to this definition, an owner $\left(h^{\prime}>0\right)$ is not liquidity constrained so long as it saves sufficiently more (borrows less) than the minimum downpayment in the house (lqas $>0.1667 y)$; a renter $\left(h^{\prime}=0\right)$ is not constrained if financial assets are sufficiently large $\left(b^{\prime}<-0.1667 y\right)$.

19 The baseline model predicts that 70 percent of renters and 31 percent of homeowners are liquidity constrained; and that 67 percent of impatient agents and 2 percent of patient agents are liquidity constrained.
} 
explore them in detail here. ${ }^{20}$ Instead, we focus on the endogenous component of heterogeneity, which reflects the fact that individuals with different ages and income histories accumulate different amounts of wealth over time; in turn, heterogeneity in wealth implies different individual responses to the same shock.

Workings of the Model. We focus on the response of aggregate hours to a technology shock, since movements in hours are the key element of the propagation mechanism in models that rely on technology shocks as sources of aggregate fluctuations. In particular, we study how the wealth distribution and its composition shape agents' responses to shocks. To fix ideas, consider a stripped-down version of the budget constraint of a working individual that keeps wealth constant between two periods: $b_{t}=b_{t-1}$ and $h_{t}=h_{t-1} \cdot{ }^{21}$ Abstracting from taxes and pensions, this implies the following budget constraint:

$$
c_{t}=w_{t} \eta_{a} z_{t} l_{t}+\xi_{t},
$$

where $\xi_{t}=-\left(R_{t}-1\right) b_{t-1}-\delta_{H} h_{t-1}$ measures the resources besides wages that can be used to finance consumption: ${ }^{22}$ the term $(1-R) b$ is net interest income; the term $\delta_{H} h$ is the maintenance cost required to keep housing unchanged. Different values of $\xi$ map into different positions of the agents along the wealth distribution. For a wealthy homeowner (negative $b$ ), $\xi$ is positive and large, and wage income is a small fraction of consumption $c$. For a renter, $h=0$; in addition, assuming that the renter is not saving, $b=0$, so that $\xi=0$ too. For a homeowner with a mortgage (positive $b$ ), $\xi$ is negative. Normalize $\eta_{a}=1$ and set aside idiosyncratic shocks, so that $z_{t}=1$ at all times. Assuming that $\xi$ stays constant, the log-linearized budget constraint becomes, denoting with $\widehat{x} \equiv \frac{x_{t}-x}{x}$, where $x$ is the steady-state value of a variable:

$$
\widehat{c}=\frac{w l}{c}(\widehat{w}+\widehat{l})
$$

\footnotetext{
20 See for instance the work of Ríos-Rull (1996) and Gomme et al. (2004).

21 Obviously, the optimal decisions involve the joint choice of (1) consumption, (2) housing, (3) debt and (4) hours worked. By assuming that housing and debt remain constant across two subperiods, we can study the joint determination of consumption and hours by focusing on the budget constraint and the Euler equation for labor supply only. This is a reasonable assumption for small shocks (such as aggregate shocks).

${ }^{22}$ Renters have constant shares of housing and nonhousing consumption, so that $c_{t}=\left(w_{t} \eta_{a} z_{t} l_{t}+\xi_{t}\right) /(1+j)$, where $j$ is the ratio of housing expenditure to nondurable consumption. With minor modifications, the arguments in the text carry over to this case, since $\xi$ cannot be negative for renters.
} 
This constraint can be interpreted as an equation dictating how much the household needs to work to finance a given consumption stream, given the wage. The larger the desired consumption $\widehat{c}$, the larger the required hours $\widehat{l}$ needed to finance the consumption stream, with an elasticity of hours to consumption given by consumption-wage income ratio $(c / w l) \equiv \phi$. For a wealthy individual, $\phi$ is high and larger than one, since labor income is a small share of total earnings; for a renter without assets, $\phi=1$; for an indebted homeowner, $\phi<1$, reflecting the need to use part of the earnings to finance maintenance costs and to service the mortgage. In other words, a wealthy person needs to increase hours by more than 1 percent to finance a 1 percent rise in consumption, since labor income is less than consumption; an indebted homeowner needs to increase hours by less than 1 percent to finance a 1 percent rise in consumption, because of the leverage effect; a renter without assets needs to increase hours 1 for 1 with consumption.

The other key equation determining hours is the standard labor supply schedule. Letting $\zeta$ denote the steady-state Frisch labor supply elasticity, this curve reads as

$$
\widehat{l}=\zeta(\widehat{w}-\widehat{c}) .
$$

Combining equations 23 and 24 yields:

$$
\widehat{l}=\zeta\left(\frac{\phi-1}{\phi+\zeta}\right) \widehat{w} .
$$

Take the wage as the exogenous driving force of the model, since an exogenous rise in productivity exerts a direct effect on the wage. Whether the rise in the wage leads to an increase in hours depends on whether the consumption-wage income ratio, $\phi$, is smaller or larger than one. In other words, all else equal, borrowers $(\phi<1)$ are more likely to reduce hours following a positive wage shock, whereas savers $(\phi>1)$ are more likely to increase them.

For the economy as a whole, the response of total hours to a wage change will be an average of the labor supply responses of all households. If individual labor schedules were linear in net wealth, the aggregate labor supply response would be linear in average wealth, and wealth distribution would not affect labor supply. There are, however, two main forces that undo the linearity. First, retirees do not work, so any transfer of wealth to and from them could affect how 
the workers respond to wage shocks. Second, the interaction between borrowing constraints and housing purchases creates an interesting nonlinearity. Above, we have assumed that households do not change wealth in response to a shock in the wage. However, if households switch from renting to owning (or if they increase their house size) in good times, they typically need to save for the downpayment. This increases the incentive to work: intuitively, if the individual wants to keep consumption constant when he buys the house, he needs to work more hours. This effect creates comovement between hours and housing purchases. ${ }^{23}$ In particular, it reinforces the correlation between hours and housing demand in periods when a large fraction of the population has, all else equal, low net worth.

Business Cycle Statistics. In HP-filtered U.S. data, the variability of housing investment is large, with a standard deviation that is between three and four times that of GDP (in the period 1952-1982). Also, housing investment is procyclical, with a correlation with GDP around 0.9. Together, these two facts imply that the growth contribution of housing investment to the business cycle is larger than its share of GDP. Household mortgage debt is strongly procyclical from 1952 to 1982, but it becomes less procyclical after, with a correlation with GDP that drops from 0.78 to 0.43 . Table 3 compares the benchmark model with the data. Overall, our baseline model does a good job in reproducing the relative volatility of each component of aggregate demand. In particular, it can account for about three quarters of the variance of housing investment. On the contrary, the model overpredicts the volatility of aggregate consumption. The volatility of business investment is only slightly lower than in the data. As in many RBC models without an extensive margin of work and without direct shocks to the labor supply, our model underpredicts the volatility of hours (0.33 percent in the model, 1.6 percent in the data).

Turning to debt, the model does well in reproducing its cyclical behavior. ${ }^{24}$ The key to this result is that the bulk of the debt holders (mostly impatients) upgrades housing in good times

\footnotetext{
23 The limiting case of zero forced savings would be the case in which no downpayment is needed to buy a house. In that case the individual can keep consumption constant at the time of the purchase without increasing hours worked if transaction costs are zero. If the individual has to pay the transaction cost, this provides an incentive to work more at the time of the purchase. Campbell and Hercowitz (2005) propose a similar argument to discuss the relationship between hours and durable purchases.

24 We define household debt as $D_{t}=\int_{b>0} b_{a}\left(x_{t} ; \beta\right) d \Phi_{t}$ (that is, the average of the household liabilities).
} 
by taking out a (larger) mortgage. At the same time, the model overpredicts the volatility of debt itself: the standard deviation of the model variable is about four times larger than in the data. We suspect that the reason for the higher volatility of debt in the model has to do with the simplifying assumption that only one financial asset is available, whereas in the data some households (especially the wealthy) own simultaneously a mortgage and other financial assets. If debt of low-wealth households is more volatile than debt of high-wealth households, our model variable can exhibit more volatility than its data counterpart.

One dimension where it is useful to compare the model with the data pertains to home sales. In our model, we count a sale as every instance in which a household pays the transaction cost to change its housing: this involves own-to-own, rent-to-own and own-to-rent transitions. By this metric, the average turnover rate in the model (the ratio of sales to total houses) is 4 percent, a number that matches the 3.9 percent in the data. ${ }^{25}$ Moreover, the model correlation between turnover rate and GDP is 0.39 , and the standard deviation is 0.29 . The corresponding numbers from the data are 0.69 and 0.54 . The positive correlation between sales and economic activity that the model captures reflects the presence of liquidity constraints: when the economy is in recession and household balance sheets have deteriorated, the potential movers in the model find their liquidity so impaired, whether they are owners or renters, that they are better off staying in their old house rather than attempting to move and paying the transaction cost.

\section{Effects of Lower Downpayments and Higher Risk}

Having shown above that the model roughly captures postwar U.S. business cycles, we now consider the implications of two experiments. In the first, we lower the downpayment from 25 to 15 percent. In the second, we increase the idiosyncratic risk faced by households, changing the unconditional standard deviation of income $\sigma_{Z}$ from 0.30 to 0.45 . Our experiment is intended to mirror two of the main changes that have occurred in the U.S. economy since the mid 1980s.

\footnotetext{
${ }^{25}$ The turnover rate in the data is constructed as the sum of sales of existing single-family homes (source: National Association of Realtors) plus new single-family homes sold (from Census Bureau), divided by the total housing stock (from Census Bureau). The series starts in 1968.
} 
The model results are in Table 4.

A Decline in Downpayments. Lower downpayments (column 2 in Table 4) lead to an increase in the homeownership rate (from 64 to 76 percent) and to a higher level of debt (from 31 to 50 percent of GDP). Smaller downpayments allow more housing ownership among the portion of the population with very little net worth. While debt is higher, the increase in homeownership works to keep total wealth inequality unchanged: financial wealth inequality is higher, but housing wealth inequality is lower. Turning to business cycles, the rise in $m_{H}$ tends to reduce the volatility of housing investment, from 6.42 to 5.94 percent, for two reasons. The first reason has to do with adjustment costs: on average, because of adjustment costs, homeowners modify their housing little over time relative to renters. The second motive operates through the interaction of labor supply and housing purchases. As we explained above, indebted homeowners are more likely, compared to renters, to reduce hours in response to positive technology shocks, so their presence dampens aggregate shocks. Therefore, the higher homeownership rate induced by looser borrowing constraints reduces aggregate volatility. ${ }^{26}$

An Increase in Individual Earnings Volatility. Column 3 in Table 4 shows that, following a rise in $\sigma_{Z}$, the homeownership rate falls from 64 to 59 percent: higher risk makes individuals more reluctant to buy an asset that is costly to change. All else equal, the lower homeownership rate would tend to increase the volatility of housing investment, since renters change housing consumption more often. However, this effect is more than offset by the behavior of those who remain homeowners: these people are now more reluctant to change their housing consumption (relative to a world with less individual risk). This occurs because modifying housing, in the

\footnotetext{
${ }^{26}$ A similar intuition has been proposed in Campbell and Hercowitz (2005), who show that financial innovation alone can explain more than half of the reduction in aggregate volatility in a model with borrowers and lenders and downpayment constraints. Aside from modeling differences (our model considers the owning/renting margin and addresses issues related to life cycle, lumpiness and risk that are absent in their setup), the intuition they offer for their result carries over to our model, but we find that the effect of lower downpayment requirements is quantitatively smaller. We conjecture that the differences depend on one modeling assumption: in our setup, indebted homeowners mitigate aggregate volatility, but this effect is partly offset by the wealthier homeowners (the creditors) who tend to increase aggregate volatility by working relatively more in response to positive aggregate shocks; instead, Campbell and Hercowitz assume that labor supply of wealthy homeowners is constant, thus killing this offsetting mechanism.
} 
presence of transaction costs, depletes holdings of liquid assets and increases the utility cost of a negative idiosyncratic shock, thus increasing the option value of not adjusting the stock for given changes in net worth. Quantitatively, the higher earnings volatility reduces the standard deviation of housing investment from 6.42 to 5.52 percent. Moreover, higher income volatility also reduces the sensitivity of debt to aggregate shocks, since debt is used to finance housing purchases, and housing purchases respond less to shocks.

Combining Lower Downpayments and Higher Volatility. The last column of Table 4 shows the effects of combining lower downpayments and higher volatility. The two forces together predict an increase in homeownership rates from 64 to 67 percent. The data counterpart is a two percentage points rise, from 64 to 66 percent. Moreover, the joint effect of these two forces makes debt less procyclical, as in the data. The correlation between debt and output falls from 0.71 to 0.39 , a change that is remarkably similar to the data (from 0.78 to 0.43 , see Table 1 ). ${ }^{27}$ Together, lower downpayments and high idiosyncratic volatility reduce the standard deviation of GDP from 2.09 to 2.03 percent, and the standard deviation of housing investment from 6.42 to 5.04. percent. When these numbers are compared to the data, the two changes combined can account for 13 percent of the variance reduction in GDP and about 60 percent of the variance reduction in housing investment.

Our interpretation of these results is as follows: in response to lower downpayments and higher income volatility, leveraged households become more cautious in response to aggregate shocks, thus changing less borrowing and housing demand when aggregate productivity changes. ${ }^{28}$ This is especially true for housing, relative to other categories of expenditure, since housing is a highly durable good and is subject to adjustment costs. Because individuals are reluctant to adjust their housing consumption during uncertain times, the sensitivity of hours to aggregate shocks falls

\footnotetext{
${ }^{27}$ Likewise, the correlation between debt and consumption falls in the model from 0.85 to 0.58 , a decline similar to the data (from 0.72 to 0.37 ).

${ }^{28}$ Higher uncertainty in itself reduces the willingness to borrow, whereas lower downpayments lead to an increase in debt. In our baseline calibration, the second effect dominates - as shown in table 4, the ratio of debt to GDP rises from 0.31 to 0.35 when both changes are present. As a consequence, in the late period individuals are more cautious, even if they hold more debt. For this reason, the fraction of liquidity constrained households in the model falls from 45 to 38 percent.
} 
too. As a consequence, even if the volatilities of consumption and business investment are not changing, total output is less volatile.

In Figure 7, each panel shows average debt, hours and housing positions by age in the lowest and the highest aggregate state. The top panel plots the calibration with high downpayments and low idiosyncratic risk (the period 1952-1982): changes in the aggregate state generate large differences in debt, housing and hours. The bottom panel plots the case with low downpayments and high idiosyncratic risk (the period 1983-2010): changes in the aggregate state generate smaller differences in debt, housing, and hours, thus illustrating how these variables become less volatile and less procyclical.

Figure 8 plots the model dynamics when technology switches from its average value to a higher value (about 1 percent rise) in period 1. The responses are larger in the earlier period. On impact, housing falls before rising strongly in period 1. This result is well known in the household production literature (see, for instance, Greenwood and Hercowitz 1991 and Fisher 2007). In models with housing and business capital, business capital is useful for producing more types of goods than housing capital. Hence, after a positive productivity shock, the rise in the marginal product of capital implies that there is a strong incentive to move resources out of the housing to build up business capital, and only later is housing accumulated. The key aspect to note here is that higher idiosyncratic risk and lower downpayment requirements dampen the incentive to adjust housing capital, so that housing investment becomes less volatile.

Our result that higher individual uncertainty reduces the volatility of aggregate housing investment echoes the results of papers that study how durable purchases respond to changes in income uncertainty in $(S, s)$ models resulting from transaction costs. Eberly (1994), using data from the Survey of Consumer Finances, considers automobile purchases in presence of transaction costs: she finds that higher income variability broadens the range of inaction, and that the effect is larger for households that are liquidity constrained. Foote, Hurst and Leahy (2000) find a similar result using data on car holdings from the Consumer Expenditure Survey, and offer an explanation that involves the presence of liquidity constraints and precautionary saving: adjusting the capital stock for people with low levels of net worth depletes holdings of 
liquid assets and increases the utility cost of a negative idiosyncratic shock, thus increasing the option value of not adjusting the stock for given changes in net worth.

\section{Debt and Housing in a Great Recession Experiment}

The finding that housing and debt are less sensitive to aggregate shocks when downpayments are low and idiosyncratic risk is high can account for part of the Great Moderation, but is at odds with the events of the 2007-2009 financial crisis, when both housing and debt fell substantially. Explaining the crisis is beyond the scope of this paper, but in this section we show that our model expanded to take into account the "credit crunch" can generate, at least qualitatively, the observed response of housing and debt in the Great Recession. We extend the stochastic structure of the model so that, when the worst technology shocks hit, credit standards get tighter too, in the form of lower loan-to-value ratios and higher costs of financial intermediation (higher borrowing interest rates). In other words, consistent with the post-2007 evidence ${ }^{29}$ recessions are now a combination of negative financial and negative technology shocks occurring simultaneously. We implement this scenario by assuming that the maximum loan-to-value ratio $m_{H}$ changes over time as a function of total factor productivity, $A_{t}$ : formally, $m_{H, t}=m_{H}\left(A_{t}\right)$. Moreover, we also introduce an additional cost of financial intermediation in the form of an interest rate premium $r_{t}^{p}=r^{p}\left(A_{t}\right)$ to be paid by debtors. The budget constraint for a home buyer become respectively:

$$
\begin{aligned}
c_{t}+h_{t}+\Psi\left(h_{t}, h_{t-1}\right) & =y_{a t}+b_{t}-\left(R_{t}+\mathcal{I}\left(b_{t-1}>0\right) r_{t}^{p}\right) b_{t-1}+\left(1-\delta_{H}\right) h_{t-1} \\
\text { with } \quad b_{t} & \leq \min \left(m_{H, t} h_{t}, m_{Y} \Re_{t}\right), c_{t} \geqslant 0, l_{t} \in(0, \bar{l}),
\end{aligned}
$$

where $\mathcal{I}\left(b_{t-1}>0\right)$ is the indicator function equal to 1 if the household is a net debtor, 0 otherwise. The state vector $x_{t}$ remains unchanged with respect to the benchmark model, and so does the equilibrium definition. In the calibration, we let $m_{H}$ drop by 6 percentage points in correspondence of the two lowest values of $A_{t}$, and leave it constant for all other values of $A_{t} \cdot{ }^{30}$

\footnotetext{
29 Jermann and Quadrini (forthcoming) document that credit shocks have played an important role in capturing U.S. output during the last decades.

30 Total factor productivity is discretized using a 7-state Markov chain (see Appendix). For the lowest two aggregate productivity levels: in the period 1952-1982, $m_{H, t}=0.70$, and in the period $1983-2010, m_{H, t}=0.80$.
} 
We set the values of the interest rate premium at $0.75 \%$ for the two lowest aggregate productivity realizations, in both periods ( $r^{p}$ is equal to zero for all other values of $\left.A_{t}\right)$.

We find that this simple modification of the model can qualitatively account for the behavior of housing and debt in the most recent events. Figure 9 shows the impulse responses to positive and negative productivity shocks, comparing the early period with the late period (defined as in the baseline exercise). In the late period, debt, housing and GDP respond less to positive shocks, so that one finds evidence of the Great Moderation so long as the economy is lucky enough not to be hit by (too negative) negative shocks. When the worst recessionary shocks hit, however, the decline in debt and in housing purchases are considerably larger in the late period than in the early period. In other words, when leverage is high, the housing sector can better absorb "small" business-cycle shocks, but becomes more vulnerable to large negative shocks that result in a credit crunch: these shocks cause highly-leveraged households to sharply reduce their debt and housing purchases. ${ }^{31}$

\section{Sensitivity Analysis}

We discuss in this section four alternative versions of the model where we modify the calibration used in our benchmark.

Discount Factor. To analyze the model with homogeneous discounting, we modify the calibration for the discount factor $(\beta=0.978)$ and for the relative utility from renting $(\theta=0.922)$ in order to achieve the same homeownership rate and interest rate as in our baseline. As shown in Table 5, the volatilities of housing investment and output are now slightly higher than in the baseline calibration, but the correlations of housing investment and of hours with output fall: this result occurs because fewer people are close to the borrowing limit (only 15 percent of households are liquidity-constrained) and in need of increasing hours to finance the downpayment in good times. In addition, with a single discount factor, very few people hold debt in equilibrium, and the distribution of wealth is more egalitarian than in the data: the Gini coefficient for wealth is

\footnotetext{
${ }^{31}$ Incidentally, we note that the volatility of GDP is still smaller in the late than in the early period calibration.
} 
0.53, lower than in the data and in the benchmark model. The model predicts, unlike the data, a negative correlation between turnover and GDP: with a single discount rate, more housing capital reallocation occurs in bad times.

Persistence of the Income Process. One key parameter is the persistence of income shocks. Our benchmark sets $\rho_{Z}=0.9$. The robustness analysis in Table 5 shows that, holding total income risk constant, some of the model properties are a non-monotonic function of $\rho_{Z}$. When the shocks are not very persistent $\left(\rho_{Z}=0.7\right)$, the equilibrium level of debt is relatively low, fewer people are at the liquidity constraint, and debt and housing investment are less volatile and slightly less cyclical. Conversely, when income shocks are highly persistent $\left(\rho_{Z}=0.95\right)$, more people are liquidity constrained, but more people are lucky for a spell long enough to afford the downpayment for a house and to keep housing and debt relatively unchanged in response to shocks. ${ }^{32}$ In other experiments not reported in the Table, we have found that only for intermediate values of the persistence coefficient (between 0.85 and 0.92 ), can the model account for both the high volatility of housing investment and the high correlation of debt with economic activity. Moreover, for values of $\rho_{Z}$ above 0.95 , housing turnover is negatively correlated with GDP, and housing is negatively correlated with business investment.

Housing Transaction Costs. We consider two polar cases, zero and high transaction costs. With no transaction costs, the standard deviation of housing investment, which is 6.42 percent in the baseline, rises to 10.42 percent (see Table 5). ${ }^{33}$ Because houses are less risky, homeownership rises, from 64 to 68 percent. Aggregate volatility falls: housing and nonhousing capital become closer substitutes as means of saving, and the higher volatility of housing investment is offset by the reduced covariance between housing and nonhousing investment. The correlation between

\footnotetext{
32 To keep our experiments simple and easier to interpret, we do not attempt here at recalibrating some of the other parameters in order to match the same targets as in the benchmark model.

33 Thomas (2002) argues that lumpiness of fixed investment at the level of a single production unit bears no implications for the behavior of aggregate quantities in an otherwise standard RBC model. Her argument rests on the representative household's desire to smooth consumption over time, a desire that undoes any lumpiness at the level of the individual firm. Our sensitivity analysis shows that there are differences between the models with and without adjustment cost. Adjustment costs imply smaller housing adjustment at the aggregate level, but larger housing adjustments (when they occur) at the individual level.
} 
housing and non-housing investment, which is 0.18 in the baseline ( 0.36 in the data), becomes -0.40 in absence of transaction costs. It is interesting to relate this result to the household production literature, which models adjustment costs either as convex or using a time-to-build specification. ${ }^{34}$ Fisher (2007) argues that the household production model predicts that housing and business investment are negatively correlated, unless one assumes that household capital is complementary to business capital and labor in market production. Here, we note that our baseline model with nonconvex housing adjustment costs reproduces (unlike the model with no transaction costs) the positive correlation between housing and business investment that one finds in the data: sooner or later these costs must be paid in order to consume more housing, and it is better to pay them in good times, when the marginal utility of consumption is low. Moreover, impatient renters cannot wait to become homeowners, thus effectively buying houses and borrowing (i.e. selling claims on capital) after a positive productivity shock.

Table 5 also reports the results for the high adjustment cost case $(\psi=8 \%)$. The high $\psi$ model predicts low housing turnover (2.1 percent) relative to the data (4 percent), and an acyclical behavior of housing sales (sales are procyclical both in the data and in the benchmark model). Such model severely underpredicts the volatility of housing investment. We conjecture that moving shocks (when combined with income shocks) could restore the level of housing turnover that is observed in the data even in the presence of high transaction costs. It is not clear, however, whether moving shocks could make turnover procyclical, unless they are more likely to happen in good times.

Housing Depreciation. The last column of Table 5 reports the results when the housing depreciation rate is lowered from 5 to 3 percent. The performance of some of the model's second moments worsens considerably. Housing investment becomes too volatile, the cyclicality of housing investment is much lower than in the data, and the model fails to match the comovement of housing with business investment.

\footnotetext{
34 See for instance Gomme, Kydland and Rupert (2001).
} 


\section{Conclusions}

In this paper, we develop an equilibrium business cycle model where houses can be used as collateral, purchased or rented, and adjusted at a large cost. The resulting dynamics of housing investment and household debt are realistic not only at the macroeconomic level, but also at the level of individual household behavior: even if agents only infrequently adjust their housing choice, housing investment is the most volatile component of aggregate demand in our model, a result that is mirrored in the data. Our model accounts for the procyclicality and volatility of housing investment, as well as for the procyclicality of household debt. The model can also explain why housing investment has become relatively less volatile, and household debt less procyclical, as a consequence of increased household-level risk and lower downpayment requirements, two structural changes that have occurred in the U.S. economy around the mid-1980s. We further extend the model to account for a "Great Recession" episode characterized by negative technology shocks coupled with tighter credit conditions. This simple modification generates an interesting nonlinearity which is consistent with recent events: when leverage is high, housing, debt and output respond less to positive shocks (as in the Great Moderation) but are relatively more vulnerable to negative shocks, making a recession worse (as in the Great Recession).

Despite its complexity, the model precludes an examination of certain aspects of housing behavior that may be relevant for understanding business cycle fluctuations. One limitation is that we have not endogenized house prices. ${ }^{35}$ There are two main reasons for our choice. First, allowing for variable house prices would require specifying a two-sector model with housing and nonhousing goods that are produced using different technologies, or a model with different price stickiness in housing and nonhousing goods; and would probably require a rich array of shocks in addition to productivity shocks, since we know from existing studies that technology shocks alone cannot quantitatively explain observed movements in house prices: all of this would considerably increase computational costs. Second, although movements in house prices are economically important, cyclical fluctuations in the price of housing are smaller than the corresponding fluc-

\footnotetext{
35 The recent papers by Kiyotaki, Michaelides and Nikolov (2011), Favilukis, Ludvigson and Van Nieuwerburgh (2009), and Ríos-Rull and Sánchez-Marcos (2008) are steps in this direction.
} 
tuations in its quantity, which are the focus of our paper: for example, over the period 1970-2008, the standard deviation of year-on-year growth in real housing investment is 14 percent, while the corresponding number for real house prices is 3.7 percent. ${ }^{36}$

A second aspect of our model is that it does not explicitly consider mortgage default. Under the assumption that all debt is collateralized, and given that no shock is large enough to cause agents to owe on their house more than they are worth, agents would not find it optimal to default on their debts, even if they had this option. However, default is an important device against risk in an economy where housing values decline in recessions. In Appendix $\mathrm{C},{ }^{37}$ we sketch an extension of our model that dispenses from aggregate productivity shocks and features large housing depreciation shocks as the main source of business cycles. The model allows debtors to default on their mortgage, at the cost of losing their house and being excluded from the mortgage market. We assume that lenders cannot observe individual borrowers' characteristics, but can charge a higher interest rate on all loans in states of the world where default rates are higher to satisfy a zero profit condition. In this setup, indebted households will weigh the utility premium benefit of being homeowners against the cost of servicing their debt in states where they have negative equity. When a depreciation shock destroys part of the housing capital, borrowing rates rise, and highly leveraged individuals find themselves underwater, and decide to default on their debt, becoming renters. The model can be used to study how shocks to housing values interact with the mortgage default rate, interest rates, debt and the housing stock. For plausibly calibrated values, a shock that destroys 20 percent of the existing housing stock leads to a rise in defaults (from 0 to 10 percent), a rise in borrowing premia (from 0 to 1.5 percent), and a sharp decline in debt, output and housing investment.

\footnotetext{
${ }^{36}$ For house prices, we use the Conventional Mortgage Home Price Index (adjusted for inflation).

${ }^{37}$ Appendix $\mathrm{C}$ is available at https://www2.bc.edu/ iacoviel/.
} 


\section{References}

Anily, Shoshana, Jacob Hornik, and Miron Israeli (1999) 'Inferring the distribution of households' duration of residence from data on current residence time.' Journal of Business 83 Economic Statistics 17(3), 373-81

Cagetti, Marco (2003) 'Wealth accumulation over the life cycle and precautionary savings.' Journal of Business 83 Economic Statistics 21(3), 339-53

Campbell, Jeffrey R., and Zvi Hercowitz (2005) 'The role of collateralized household debt in macroeconomic stabilization.' NBER Working Papers 11330, National Bureau of Economic Research, Inc, May

Card, David (1991) 'Intertemporal labor supply: An assessment.' NBER Working Papers 3602, National Bureau of Economic Research, Inc, January

Carroll, Christopher, and Wendy Dunn (1997) 'Unemployment expectations, jumping (s,s) triggers, and household balance sheets.' In 'NBER Macroeconomics Annual 1997, Volume 12' (MIT Press)

Chambers, Matthew, Carlos Garriga, and Don E. Schlagenhauf (2009) 'Housing policy and the progressivity of income taxation.' Journal of Monetary Economics 56(8), 1116-1134

Davis, Morris A., and Francois Ortalo-Magne (2011) 'Household expenditures, wages, rents.' Review of Economic Dynamics 14(2), 248-261

Davis, Morris A., and Jonathan Heathcote (2005) 'Housing and the business cycle.' International Economic Review 46(3), 751-784

Díaz, Antonia, and María José Luengo-Prado (2010) 'The wealth distribution with durable goods.' International Economic Review 51(1), 143-170

Dynan, Karen E., Douglas W. Elmendorf, and Daniel E. Sichel (2007) 'The evolution of household income volatility.' Finance and Economics Discussion Series 2007-61, Board of Governors of the Federal Reserve System (U.S.)

Eberly, Janice C (1994) 'Adjustment of consumers' durables stocks: Evidence from automobile purchases.' Journal of Political Economy 102(3), 403-36

Favilukis, Jack, Sydney Ludvigson, and Stijn Van Nieuwerburgh (2009) 'Macroeconomic implications of housing wealth, housing finance, and limited risk-sharing in general equilibrium.' Unpublished Manuscript

Fernandez-Villaverde, Jesus, and Dirk Krueger (2004) 'Consumption and saving over the life cycle: How important are consumer durables?' 2004 Meeting Papers 357b, Society for Economic Dynamics

Fisher, Jonas D. M. (2007) 'Why does household investment lead business investment over the business cycle?' Journal of Political Economy 115, 141-168 
Fisher, Jonas D. M., and Martin Gervais (2007) 'First-time home buyers and residential investment volatility.' Working Paper Series WP-07-15, Federal Reserve Bank of Chicago

Floden, Martin, and Jesper Lindé (2001) 'Idiosyncratic risk in the united states and sweden: Is there a role for government insurance?' Review of Economic Dynamics 4(2), 406-437

Foote, Christopher, Erik Hurst, and John Leahy (2000) 'Testing the (s, s) model.' American Economic Review 90(2), 116-119

Francis, Neville, and Valerie A. Ramey (2009) 'Measures of per capita hours and their implications for the technology-hours debate.' Journal of Money, Credit and Banking 41(6), 10711097

Fraumeni, Barbara (1997) 'The measurement of depreciation in the u.s. national income and product accounts.' Survey of Current Business pp. 7-23

Gerardi, Kristopher S., Harvey S. Rosen, and Paul S. Willen (2010) 'The impact of deregulation and financial innovation on consumers: The case of the mortgage market.' Journal of Finance 65(1), 333-360

Gervais, Martin (2002) 'Housing taxation and capital accumulation.' Journal of Monetary Economics 49(7), 1461-1489

Gomme, Paul, Finn E. Kydland, and Peter Rupert (2001) 'Home production meets time to build.' Journal of Political Economy 109(5), 1115-1131

Gomme, Paul, Richard Rogerson, Peter Rupert, and Randall Wright (2004) 'The business cycle and the life cycle.' In 'NBER Macroeconomics Annual 2004, Volume 19' (MIT Press)

Greenwood, Jeremy, and Zvi Hercowitz (1991) 'The allocation of capital and time over the business cycle.' Journal of Political Economy 99(6), 1188-214

Gross, David B., and Nicholas S. Souleles (2002) 'Do liquidity constraints and interest rates matter for consumer behavior? evidence from credit card data.' The Quarterly Journal of Economics 117(1), 149-185

Guvenen, Fatih (2011) 'Macroeconomics with heterogeneity: A practical guide.' Unpublished Manuscript

Haider, Steven J (2001) 'Earnings instability and earnings inequality of males in the united states: 1967-1991.' Journal of Labor Economics 19(4), 799-836

Hall, Robert E. (2011) 'The long slump.' The American Economic Review 101(2), 431-469

Hansen, Gary D (1993) 'The cyclical and secular behaviour of the labour input: Comparing efficiency units and hours worked.' Journal of Applied Econometrics 8(1), 71-80

Hansen, Kristin A. (1998) 'Seasonality of moves and duration of residence.' Current Population Reports, Household Economic Studies, P70-66 (October), U.S. Census Bureau 
Heathcote, Jonathan, Kjetil Storesletten, and Giovanni L. Violante (2010) 'The macroeconomic implications of rising wage inequality in the united states.' Journal of Political Economy $118(4), 681-722$

Hendricks, Lutz (2007) 'How important is discount rate heterogeneity for wealth inequality?' Journal of Economic Dynamics and Control 31(9), 3042-3068

Iacoviello, Matteo, and Stefano Neri (2010) 'Housing market spillovers: Evidence from an estimated dsge model.' American Economic Journal: Macroeconomics 2(2), 125-64

Jappelli, Tullio (1990) 'Who is credit constrained in the u.s. economy?' The Quarterly Journal of Economics 105(1), 219-34

Jermann, Urban, and Vincenzo Quadrini (forthcoming) 'Macroeconomic effects of financial shocks.' The American Economic Review

Kennickell, Arthur, and Janice Shack-Marquez (1992) 'Changes in family finances from 1983 to 1989: evidence from the survey of consumer finances.' Federal Reserve Bulletin pp. 1-18

King, Robert G., and Sergio T. Rebelo (1999) 'Resuscitating real business cycles.' In Handbook of Macroeconomics, ed. J. B. Taylor and M. Woodford, 1 ed., vol. 1 (Elsevier) chapter 14, pp. 927-1007

Kiyotaki, Nobuhiro, Alexander Michaelides, and Kalin Nikolov (2011) 'Winners and losers in housing markets.' Journal of Money, Credit and Banking 43, 255-296

Krueger, Dirk, and Fabrizio Perri (2006) 'Does income inequality lead to consumption inequality? evidence and theory.' Review of Economic Studies 73(1), 163-193

Krusell, Per, and Anthony A. Smith (1998) 'Income and wealth heterogeneity in the macroeconomy.' Journal of Political Economy 106(5), 867-896

Moffitt, Robert, and Peter Gottschalk (2008) 'Trends in the transitory variance of male earnings in the u.s., 1970-2004.' Boston College Working Papers in Economics 697, Boston College Department of Economics, December

National Association of Realtors (2005) 'Structure, conduct, and performance of the real estate brokerage industry.' Technical Report

Peek, Joe, and James A. Wilcox (1991) 'The measurement and determinants of single-family house prices.' Real Estate Economics 19(3), 353-382

Poterba, James M. (1992) 'Taxation and housing markets.' In 'Canada-U.S. Tax Comparisons' (University of Chicago Press)

Queisser, Monika, and Edward Whitehouse (2005) 'Pensions at a glance: public policies across oecd countries.' MPRA Paper 10907, University Library of Munich, Germany, May

Ríos-Rull, José-Víctor (1996) 'Life-cycle economies and aggregate fluctuations.' Review of Economic Studies 63(3), 465-89 
Ríos-Rull, José-Víctor, and Virginia Sánchez-Marcos (2008) 'An aggregate economy with different size houses.' Journal of the European Economic Association 6(2-3), 705-714

Rosen, Harvey S. (1985) 'Housing subsidies: Effects on housing decisions, efficiency, and equity.' In Handbook of Public Economics, ed. A. J. Auerbach and M. Feldstein, vol. Handbook of Public Economics (North Holland)

Scholz, John Karl, Ananth Seshadri, and Surachai Khitatrakun (2006) 'Are americans saving "optimally" for retirement?' Journal of Political Economy 114(4), 607-643

Silos, Pedro (2007) 'Housing, portfolio choice and the macroeconomy.' Journal of Economic Dynamics and Control 31(8), 2774-2801

Tauchen, George (1986) 'Finite state markov-chain approximations to univariate and vector autoregressions.' Economics Letters 20(2), 177-181

Thomas, Julia K. (2002) 'Is lumpy investment relevant for the business cycle?' Journal of Political Economy 110(3), 508-534

Venti, Steven F., and David A. Wise (2001) 'Choice, chance, and wealth dispersion at retirement.' In 'Aging Issues in the United States and Japan' (University of Chicago Press)

Young, Eric R. (2010) 'Solving the incomplete markets model with aggregate uncertainty using the krusell-smith algorithm and non-stochastic simulations.' Journal of Economic Dynamics and Control 34(1), 36-41 


\section{Appendix A: Computational Details}

We solve for the model equilibrium using a computational method similar to the one used in Krusell and Smith (1998). The value and policy functions are computed on grids of points for the state variables, and then approximated with linear interpolation at points not on the grids (with the exception of the policy functions for housing, that are defined only on points on the grid). The algorithm consists of the following steps:

1. Specify grids for the state space of individual and aggregate state variables.

The number of grid points was chosen as follows: 7 points for the aggregate shock, 3 values for the idiosyncratic shock, 25 points for the housing stock, and 500 points for the financial asset. ${ }^{38}$ For aggregate capital, we choose a grid of 15 equally spaced points in the initial range $\left[0.8 K^{*}, 1.2 K^{*}\right]$, where $K^{*}$ denotes the average value of this variable in the simulations. The range is then updated at each iteration consistently with the simulated $K$, assigning as its boundaries the minimum and the maximum simulated values.

2. Guess initial coefficients $\left\{\omega_{i}^{A}\right\}_{A \in \widetilde{A}, i=0,1}$ for the linear functions that approximate the laws of motion of capital and labor:

$$
\begin{aligned}
K_{t} & =\omega_{0}^{A}+\omega_{1}^{A} K_{t-1}, \\
L_{t} & =\omega_{2}^{A}+\omega_{3}^{A} K_{t-1} .
\end{aligned}
$$

Because factor prices (wages and interest rates) only depend on aggregate capital and labor in equilibrium, this approach is equivalent to assuming that individuals forecast these factor prices using a function of $K_{t-1}$ for each value of the aggregate state $A$.

3. Starting from age $T$ backward, compute optimal policies as a function of the individual and aggregate states, solving first the homeowner's and renter's problems separately. ${ }^{39}$ Notice that the intra-temporal optimal value for labor hours as a function of consumption and productivity shock for ages $a \leq \widetilde{T}$ is the following: ${ }^{40}$

$$
l_{a, t}=\bar{l}-\frac{\tau c_{a, t}}{w_{t} \eta_{a} z_{t}}
$$

which allows one to derive consumption before age $\widetilde{T}$ directly from the budget constraint. For the homeowner:

$$
c_{a, t}=\frac{w_{t} \eta_{a} z_{t} \bar{l}-R_{t} b_{a, t-1}+b_{a, t}+\left(1-\delta_{H}\right) h_{a, t-1}-h_{a, t}-\Psi\left(h_{a, t}, h_{a, t-1}\right)}{1+\tau}
$$

so that the per-period utility function for $a \leq \widetilde{T}$ can be transformed as follows:

$$
\widetilde{u}\left(c_{a, t}, h_{a, t}, w_{t} z_{t}\right)=(1+\tau) \log c_{a, t}+j \log h_{a, t}+\tau \log \left(\tau / w_{t} \eta_{a} z_{t}\right) .
$$

\footnotetext{
${ }^{38}$ The upper bound for the housing grid and the lower bound for debt are chosen wide enough so that they never bind in the simulations.

${ }^{39}$ In computation, we exploit the strict concavity of the value function in the choice for assets as well as the monotonicity of the policy function in assets (for the homeowner problem, the monotonocity is for any given choice of the housing stock).

${ }^{40}$ We prevent individuals from choosing negative hours.
} 
For the tenant, taking into consideration the intra-temporal condition for optimal house services to rent:

$$
c_{a, t}=\frac{w_{t} \eta_{a} z_{t} \bar{l}-R_{t} b_{a, t-1}+b_{a, t}+\left(1-\delta_{H}\right) h_{a, t-1}-\Psi\left(0, h_{a, t-1}\right)}{1+\tau+j}
$$

so that the per-period utility function for $a \leq \widetilde{T}$ can be transformed as follows:

$$
\widetilde{u}\left(c_{a, t}, p_{t}, w_{t} z_{t}\right)=(1+\tau+j) \log c_{a, t}+j \log \left(j \theta / p_{t}\right)+\tau \log \left(\tau / w_{t} \eta_{a} z_{t}\right) .
$$

As a consequence, the homeowner's dynamic optimization problem entails solving for policy functions for $b$ and $h$ only, while the renter's one consists in solving for $b$ only. The problems of the retired people $(a>\widetilde{T})$ are similar to the above, where we set $\tau=0$.

4. Draw a series of aggregate and idiosyncratic shocks according to the related stochastic processes. Draw a series of "death" shocks according to the survival probabilities. Use the (approximated) policy functions and the predicted aggregate variables to simulate the optimal decisions of a large number of agents for many periods. In the simulations, we perform linear interpolation between grid points for $b^{\prime}$, but we restrict the choices of $h^{\prime}$ to lie on the grid. We simulate 90,000 individuals for 5,000 periods, discarding the first 200 periods. ${ }^{41}$ Compute the aggregate variables $K$ and $L$ at each $t$.

5. Run a regression of the simulated aggregate capital and the simulated aggregate labor on lagged aggregate capital, retrieving the new coefficients $\left\{\omega_{i}^{A}\right\}$ for the laws of motion for $K$ and $L$. We repeat steps 3 and 4 until convergence over the coefficients of the regressions. We measure goodness of fit using the $R^{2}$ of the regressions: they are always equal to 0.997 or higher at convergence for $K$ and around 0.95 for $L$; the corresponding wage rate and interest rate functions are also very accurate: the $R^{2}$ of the regression of the wage rate on aggregate $K$ is 0.999 , the $R^{2}$ of the regression of the interest rate on aggregate $K$ is 0.992 .

\footnotetext{
${ }^{41}$ We enforce the law of large numbers by making sure that the simulated fractions of ages and of labor productivity shocks correspond to the theoretical ones, by randomly adjusting the values of the shocks.
} 


\section{Appendix B: Calibrating the Income Process}

\section{The Persistence of Wage Shocks}

The (parsimonious) process for individual income productivity that we specify in the model is:

$$
\log z_{t}=\bar{z}+\rho_{Z} \log z_{t-1}+\sigma_{Z}\left(1-\rho_{Z}^{2}\right)^{1 / 2} \varepsilon_{t}, \quad \varepsilon_{t} \sim \operatorname{Normal}(0,1) .
$$

We want to pick values for $\rho_{Z}$ and $\sigma_{Z}$ that are in line with evidence.

1. Floden and Lindé (2001) estimate an AR(1) process for wages of the form in (35) and estimate (using PSID data covering the 1988-1992 period), after controlling for observable characteristics and measurement error, values of $\rho_{Z}=0.91\left(\right.$ and $\sigma_{Z}\left(1-\rho_{Z}^{2}\right)^{1 / 2}=0.21$, thus implying $\sigma_{Z}=0.5$ ).

2. Heathcote, Storesletten and Violante (2010) estimate an $\operatorname{ARMA}(1,1)$ process for wages using PSID data. Their estimate of the autoregressive component is 0.97 .

3. Scholz, Seshadri, and Khitatrakun (2006) specify and estimate a model of household log labor earnings (not wages) that controls for fixed effects, a polynomial in age, and autocorrelation in earnings. Their sample is the social security earnings records. Their estimates for married, no college, two-earners are $\rho_{Z}=0.70$ (and $\sigma_{Z}=0.43$ ).

\section{The Change in Volatility}

Several studies document the increase in the cross-sectional dispersion of earnings in the United States between the 1970s and the 1990s. This increase is often decomposed into a rise in permanent inequality (attributable to education, experience, sex, etc.) and a rise of the persistent or transitory shocks volatility. Despite some disagreement on the relative importance of these two components, the literature finds that both play a role in explaining the increase in income dispersion.

1. Moffitt and Gottschalk (2008) study changes in the variance of permanent and transitory component of income volatility using data from the PSID from 1970 to 2004. They find that the non-permanent component (transitory) variance of earnings (for male workers) increased substantially in the 1980s and then remained at this new higher level through 2004. They report (see Figure 7 in their paper) that the variance of the transitory component rose from around 0.10 to 0.22 between the 1970s and the 1980s-1990s. This corresponds to a rise in the standard deviation from 0.32 to 0.47 . Their estimate of the autocorrelation of the transitory shocks is 0.85 .

2. Using PSID data, Heathcote, Storesletten, and Violante (2010) decompose the evolution of the cross-sectional variance of individual earnings over the period 1967-2000 into the variances of fixed effects, persistent shocks, and transitory shocks. They find that the variance of persistent shocks roughly doubles during the 1975-1985 decade.

3. Haider (2001) finds that increases in earnings instability over the 1970s and increases in lifetime earnings inequality in the 1980s account in equal parts for the increase of inequality in the data. To measure the magnitude of earnings instability in year $t$, he uses the crosssectional variance of the idiosyncratic deviations in year $t$. His estimate of $\rho_{Z}$ is 0.64 . He 
finds that the unconditional standard deviation of the instability component rises from around $0.23-0.24$ to about $0.35-0.37$ during the $1980 \mathrm{~s}$.

4. Krueger and Perri (2006) model log income as an ARMA process of the kind

$$
y_{t}=z_{t}+\varepsilon_{t}, z_{t}=\rho_{Z} z_{t-1}+\sigma_{Z}\left(1-\rho_{Z}^{2}\right)^{1 / 2} \varepsilon_{t}^{z}, \varepsilon_{t}=\sigma_{\varepsilon} \varepsilon_{t}^{e}
$$

where $\varepsilon_{t}^{e}$ and $\varepsilon_{t}^{z}$ are $\operatorname{Normal}(0,1)$. They allow the innovation variances $\sigma_{\varepsilon}$ and $\sigma_{Z}$ to vary by year. They find that the values of $\sigma_{Z}$ and $\sigma_{\varepsilon}$ are respectively 0.42 and 0.28 in 1980 , and 0.52 and 0.36 in 2003. Given these numbers, the standard deviation of log income $y_{t}$ rises by 0.13 , from $\sqrt{0.42^{2}+0.28^{2}}=0.50$ to $\sqrt{0.52^{2}+0.36^{2}}=0.63$.

From this brief review, we conclude that a plausible value for the persistence of the productivity shock is around 0.9. We set the standard deviation of income to be equal to 0.3 in the early part of the sample, which is the lower bound of the estimates reported above. We set the standard deviation to 0.45 in the second part of the sample: a change of 0.15 is in the range of estimates reported by Moffitt and Gottschalk (2008). 


\section{Tables}

Table 1. U.S. Economy. Cyclical Statistics and Housing Market Facts.

\begin{tabular}{cccc}
\hline \hline & Early Period & Late Period & Whole Sample \\
& 1952.I -1982.IV & 1983.I -2010.IV & 1952.I -2010.IV \\
\hline Standard dev. & & & \\
GDP & 2.09 & 1.62 & 1.88 \\
$C$ & 0.93 & 0.83 & 0.88 \\
IH & 7.12 & 4.45 & 6.00 \\
IK & 4.90 & 5.36 & 5.11 \\
Debt & 2.23 & 2.20 & 2.21 \\
Hours & 1.60 & 1.37 & 1.49 \\
Housing Turnover & $0.54(68 . I-82 . I V)$ & 0.29 & 0.40 \\
Correlations & & & \\
IH,GDP & 0.89 & 0.75 & 0.84 \\
Debt,GDP & 0.78 & 0.43 & 0.63 \\
Hours, GDP & 0.82 & 0.86 & 0.83 \\
Turnover, GDP & 0.69 & 0.10 & 0.46 \\
IH,IK & 0.36 & 0.40 & 0.36 \\
Debt,C & 0.72 & 0.37 & 0.56 \\
Averages & & & \\
Homeownership & $64 \%$ & $66 \%$ & $65 \%$ \\
Debt to GDP & $34 \%$ & $59 \%$ & $46 \%$ \\
Housing Turnover & $3.9 \%$ & $4.3 \%$ & $3.2 \%$ \\
Gini wealth & 0.79 & 0.83 & 0.81 \\
Gini labor income & 0.40 & 0.46 & 0.83 \\
Gini consumption & 0.23 & 0.26 & 0.25 \\
\hline
\end{tabular}

Notes: $C, I H$ and $I K$ are consumption, residential fixed investment and business fixed investment respectively, divided by the GDP deflator (sources: BEA). GDP is the sum of the three series. Durables expenditures are included in $I H$. Debt is the stock of Home mortgages held by households and nonprofit organizations (source: Flow of Funds Accounts), divided by the GDP deflator. Hours are total hours worked for the entire economy from Francis and Ramey (2009). Cyclical statistics (standard deviations and correlations) for all series refer to the series logged and detrended with HP-filter (smoothing parameter 1,600). Data on inequality are from Wolff, 2010 (wealth); http://www. census.gov/hhes/www/income/data/ (income); and from Krueger and Perri, 2006 (consumption). Housing Turnover is the ratio of total home sales divided by the existing housing stock (see text for the source). 
Table 2: Parameter Values for the Benchmark Model Economy

\begin{tabular}{|c|c|c|c|}
\hline & Parameter & Value & Target/Source \\
\hline \multicolumn{4}{|l|}{ Preferences } \\
\hline Discount factor, patients & $\beta_{H}$ & 0.999 & $R=3 \%$ \\
\hline Discount factor, impatients & $\beta_{L}$ & 0.941 & Hendricks (2007) \\
\hline Fraction of impatient agents & - & $2 / 3$ & Gini coefficient of Wealth: 0.73 \\
\hline Weight on leisure in utility & $\tau$ & 1.65 & - \\
\hline Productive time & $\bar{l}$ & 2.65 & Time worked: $40 \%$ \\
\hline Weight on housing in utility & $j$ & 0.15 & $H / Y=1.4$ \\
\hline Utility, renting vs. owning & $\theta$ & 0.838 & Home ownership rate $=64 \%$ \\
\hline Utility weights (family size) & $\lambda_{a}$ & see text & Cagetti (2003) \\
\hline \multicolumn{4}{|l|}{ Life, retirement } \\
\hline Survival probabilities & $\Pi_{a}$ & see text & Decennial Life Tables \\
\hline Retirement period & $\widetilde{T}$ & 46 & Retirement age 65 years \\
\hline Pension & $P$ & $0.4 \times$ inc. & $40 \%$ average income \\
\hline \multicolumn{4}{|l|}{ Technology } \\
\hline Capital share & $\alpha$ & 0.26 & $K / Y=2.2$ \\
\hline Capital depreciation rate & $\delta_{K}$ & 0.09 & $I K / Y=0.20$ \\
\hline Housing depreciation rate & $\delta_{H}$ & 0.05 & $I H / Y=0.07$ \\
\hline Autocorrelation, technology shock & $\rho_{A}$ & 0.925 & King and Rebelo (1999) \\
\hline Standard dev., technology shock & $\sigma_{A}$ & 0.0148 & $\sigma(Y)=2.09 \%$ \\
\hline Housing transaction cost & $\psi$ & 0.05 & National Association Realtors (2005) \\
\hline Minimum House Size & $\underline{h}$ & $1.5 \times$ inc & See text \\
\hline \multicolumn{4}{|l|}{ Borrowing } \\
\hline Max debt, fraction lifetime wage & $m_{Y}$ & 0.25 & See text \\
\hline Maximum debt, fraction of house & $m_{H}$ & 0.75 & See text \\
\hline \multicolumn{4}{|l|}{ Individual income process } \\
\hline Autocorrelation, earnings shock & $\rho_{Z}$ & 0.90 & Floden and Linde (2001) \\
\hline Standard deviation, earnings shock & $\sigma_{Z}$ & 0.30 & See appendix B \\
\hline Age-dependent earnings ability & $\eta_{a}$ & see text & Hansen (1993) \\
\hline
\end{tabular}


Table 3: U.S. Economy and Baseline Model. Comparison for the Early Period.

\begin{tabular}{ccc}
\hline \hline & 1952.I -1982.IV (Early Period) & Model \\
Standard dev. & 2.09 & \\
GDP & 0.93 & 2.09 \\
$C$ & 7.12 & 1.63 \\
IH & 4.90 & 6.42 \\
IK & 2.23 & 4.16 \\
Debt & 1.60 & 8.34 \\
Hours & 0.54 (68.1-82.IV) & 0.33 \\
Housing Turnover & & 0.29 \\
Correlations & 0.89 & \\
IH, GDP & 0.78 & 0.66 \\
Debt, GDP & 0.82 & 0.71 \\
Hours, GDP & 0.69 & 0.65 \\
Turnover, GDP & 0.36 & 0.39 \\
IH,IK & 0.72 & 0.18 \\
Debt, $C$ & & 0.85 \\
Averages & $64 \%$ & \\
Homeownership & $34 \%$ & $64 \%$ \\
Debt to GDP & $3.9 \%$ & $31 \%$ \\
Housing Turnover & 0.79 & $4.0 \%$ \\
Gini wealth & 0.40 & 0.73 \\
Gini labor income & 0.23 & 0.41 \\
Gini consumption & NA & 0.26 \\
Liquidity constrained & & 0.45 \\
\hline
\end{tabular}

Notes: The model moments are based on statistics from a simulation of 5,000 periods. Liquidity constrained agents in the model are those who own liquid assets less than 16.67 percent (two months in a year) of annual income. 
Table 4: Model Predictions, Changing Downpayment Requirements and Income Volatility

\begin{tabular}{|c|c|c|c|c|}
\hline & $\begin{array}{c}\text { (1) Baseline } \\
\text { Early Period } \\
m_{H}=0.75 \\
\sigma_{Z}=0.3\end{array}$ & $\begin{array}{c}(2) \\
m_{H}=0.85 \\
\sigma_{Z}=0.3\end{array}$ & $\begin{array}{c}(3) \\
m_{H}=0.75 \\
\sigma_{Z}=0.45\end{array}$ & $\begin{array}{c}(4) \\
\text { Late Period } \\
m_{H}=0.85 \\
\sigma_{Z}=0.45\end{array}$ \\
\hline \multicolumn{5}{|l|}{ Standard Deviation } \\
\hline$G D P$ & 2.09 & 2.08 & 2.05 & 2.03 \\
\hline$C$ & 1.63 & 1.63 & 1.66 & 1.68 \\
\hline$I H$ & 6.42 & 5.94 & 5.52 & 5.04 \\
\hline$I K$ & 4.16 & 4.05 & 4.21 & 4.16 \\
\hline Debt & 8.34 & 3.04 & 2.61 & 1.44 \\
\hline Hours & 0.33 & 0.32 & 0.31 & 0.31 \\
\hline Housing Turnover & 0.29 & 0.44 & 0.21 & 0.21 \\
\hline \multicolumn{5}{|l|}{ Correlations } \\
\hline$I H, G D P$ & 0.66 & 0.69 & 0.55 & 0.54 \\
\hline Debt, GDP & 0.71 & 0.63 & 0.50 & 0.39 \\
\hline Hours, GDP & 0.65 & 0.64 & 0.47 & 0.42 \\
\hline Turnover, GDP & 0.39 & 0.77 & 0.42 & 0.28 \\
\hline$I H, I K$ & 0.18 & 0.24 & 0.08 & 0.09 \\
\hline Debt, $C$ & 0.85 & 0.77 & 0.68 & 0.58 \\
\hline \multicolumn{5}{|l|}{ Averages } \\
\hline Homeownership & $64 \%$ & $76 \%$ & $59 \%$ & $67 \%$ \\
\hline Debt to GDP & $31 \%$ & $50 \%$ & $23 \%$ & $35 \%$ \\
\hline Housing Turnover & $4.0 \%$ & $3.0 \%$ & $5.1 \%$ & $5.6 \%$ \\
\hline Gini wealth & 0.73 & 0.73 & 0.73 & 0.73 \\
\hline Gini labor income & 0.41 & 0.41 & 0.48 & 0.48 \\
\hline Gini consumption & 0.26 & 0.26 & 0.31 & 0.31 \\
\hline Liquidity constrained & 0.45 & 0.45 & 0.39 & 0.38 \\
\hline
\end{tabular}

Notes: Baseline calibration and sensitivity analysis. (1) is the baseline calibration that is targeted to the U.S. data for the period 1952-1982. In (2), we increase the loan-to-value ratio from 0.75 to 0.85 . In (3), we increase earnings volatility from 0.3 to 0.45 . In (4), we increase both loan-to-value ratio and earnings volatility so to calibrate the U.S. economy for the period 1983-2010. 
Table 5: Robustness Analysis

\begin{tabular}{ccccccccc}
\hline \hline & Data & Model & One- $\beta$ & \multicolumn{3}{c}{ Persistence } & \multicolumn{3}{c}{ Transaction cost } & Low $\delta$ \\
& & & & $\rho_{Z}=.7$ & $\rho_{Z}=.95$ & $\psi=0 \%$ & $\psi=8 \%$ & $\delta_{H}=3 \%$ \\
\hline Standard dev. & & & & & & & & \\
GDP & 2.09 & 2.09 & 2.16 & 2.08 & 2.02 & 2.05 & 2.01 & 2.05 \\
C & 0.93 & 1.63 & 1.69 & 1.69 & 1.69 & 1.69 & 1.72 & 1.68 \\
IH & 7.12 & 6.42 & 6.72 & 4.99 & 4.73 & 10.42 & 3.45 & 11.33 \\
IK & 4.90 & 4.16 & 4.83 & 4.24 & 4.12 & 4.99 & 3.95 & 5.17 \\
Debt & 2.23 & 8.34 & 14.78 & 2.68 & 2.11 & 1.68 & 2.11 & 0.68 \\
Hours & 1.60 & 0.33 & 0.39 & 0.32 & 0.27 & 0.36 & 0.27 & 0.30 \\
Housing Turnover & 0.54 & 0.29 & 0.40 & 0.16 & 0.22 & 2.14 & 0.13 & 0.16 \\
Correlations & & & & & & & & \\
IH,GDP & 0.89 & 0.66 & 0.58 & 0.61 & 0.49 & 0.34 & 0.54 & 0.30 \\
Debt,GDP & 0.78 & 0.71 & 0.72 & 0.60 & 0.58 & 0.69 & 0.39 & 0.11 \\
Hours, GDP & 0.82 & 0.65 & 0.60 & 0.50 & 0.43 & 0.45 & 0.34 & 0.45 \\
Turnover,GDP & 0.69 & 0.39 & -0.32 & 0.18 & -0.15 & 0.67 & -0.08 & 0.10 \\
IH,IK & 0.36 & 0.18 & 0.08 & 0.19 & 0.03 & -0.40 & 0.19 & -0.44 \\
Debt,C & 0.72 & 0.85 & 0.83 & 0.78 & 0.72 & 0.82 & 0.54 & 0.24 \\
Averages & & & & & & & & \\
Homeownership & $64 \%$ & $64 \%$ & $64 \%$ & $66 \%$ & $71 \%$ & $68 \%$ & $74 \%$ & $70 \%$ \\
Debt to GDP & $34 \%$ & $31 \%$ & $9 \%$ & $17 \%$ & $42 \%$ & $40 \%$ & $37 \%$ & $46 \%$ \\
Housing Turnover & $3.9 \%$ & $4.0 \%$ & $3.3 \%$ & $4.7 \%$ & $2.9 \%$ & $42.0 \%$ & $2.1 \%$ & $3.8 \%$ \\
Gini wealth & 0.79 & 0.73 & 0.53 & 0.68 & 0.73 & 0.73 & 0.72 & 0.72 \\
Gini labor income & 0.40 & 0.41 & 0.42 & 0.45 & 0.39 & 0.41 & 0.41 & 0.42 \\
Gini consumption & 0.23 & 0.26 & 0.24 & 0.23 & 0.26 & 0.26 & 0.26 & 0.26 \\
Liquidity constrained & NA & 0.45 & 0.15 & 0.30 & 0.49 & 0.47 & 0.45 & 0.45 \\
\hline
\end{tabular}

Notes: In the one- $\beta$ model, we recalibrate $\theta$ and the average $\beta$ so that the homeownership rate is $64 \%$ and the interest rate is $3 \%$, as in the baseline model. No parameter changes are made in the other models, except those noted in row 2 of the Table. 


\section{Figures}

Figure 1: Mortgage Debt, Housing Investment and GDP.
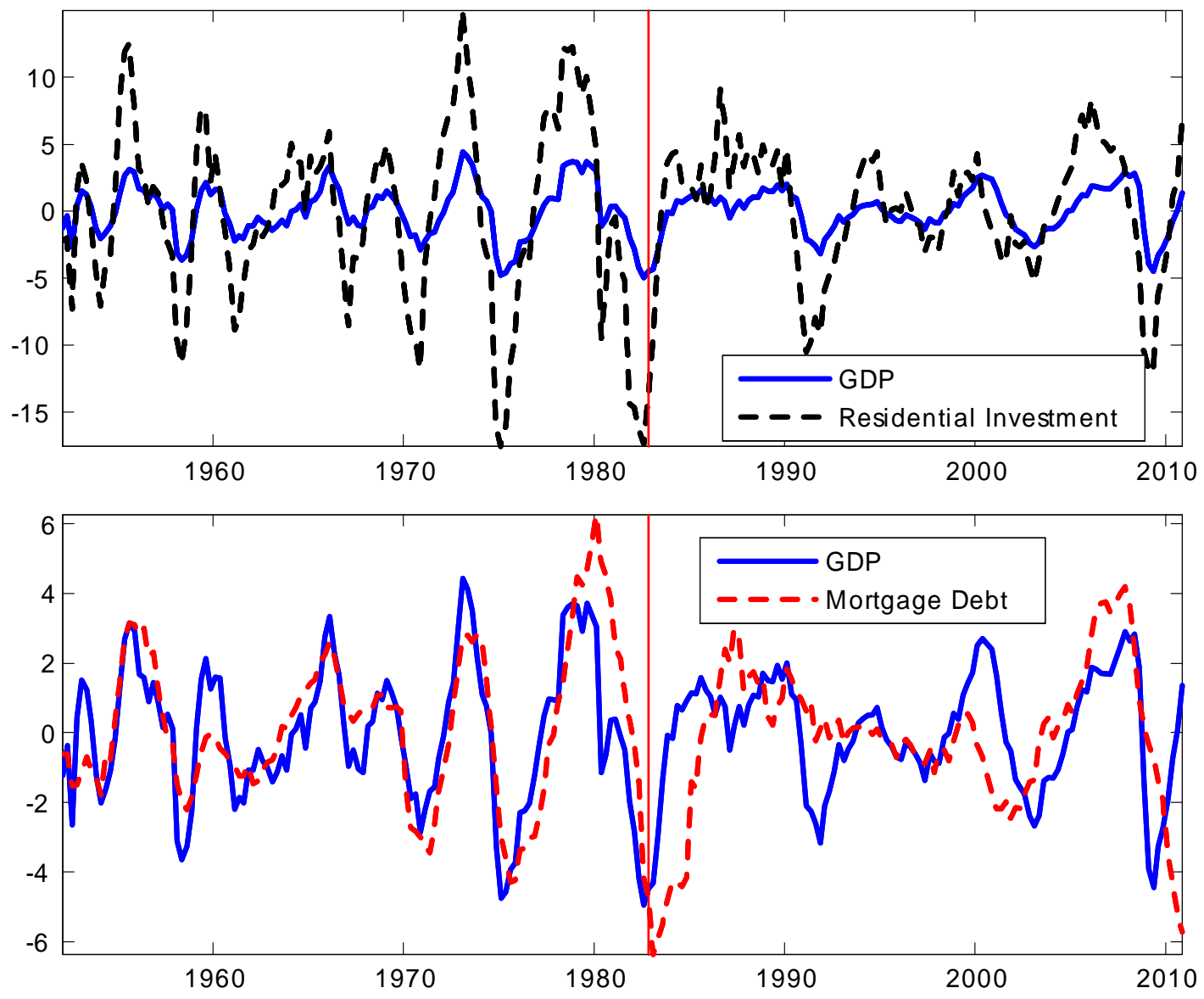

Note: Variables are inflation-adjusted, HP-filtered $(\lambda=1,600)$ and expressed in percent deviation from their trend. 
Figure 2: Efficiency and preference profiles.
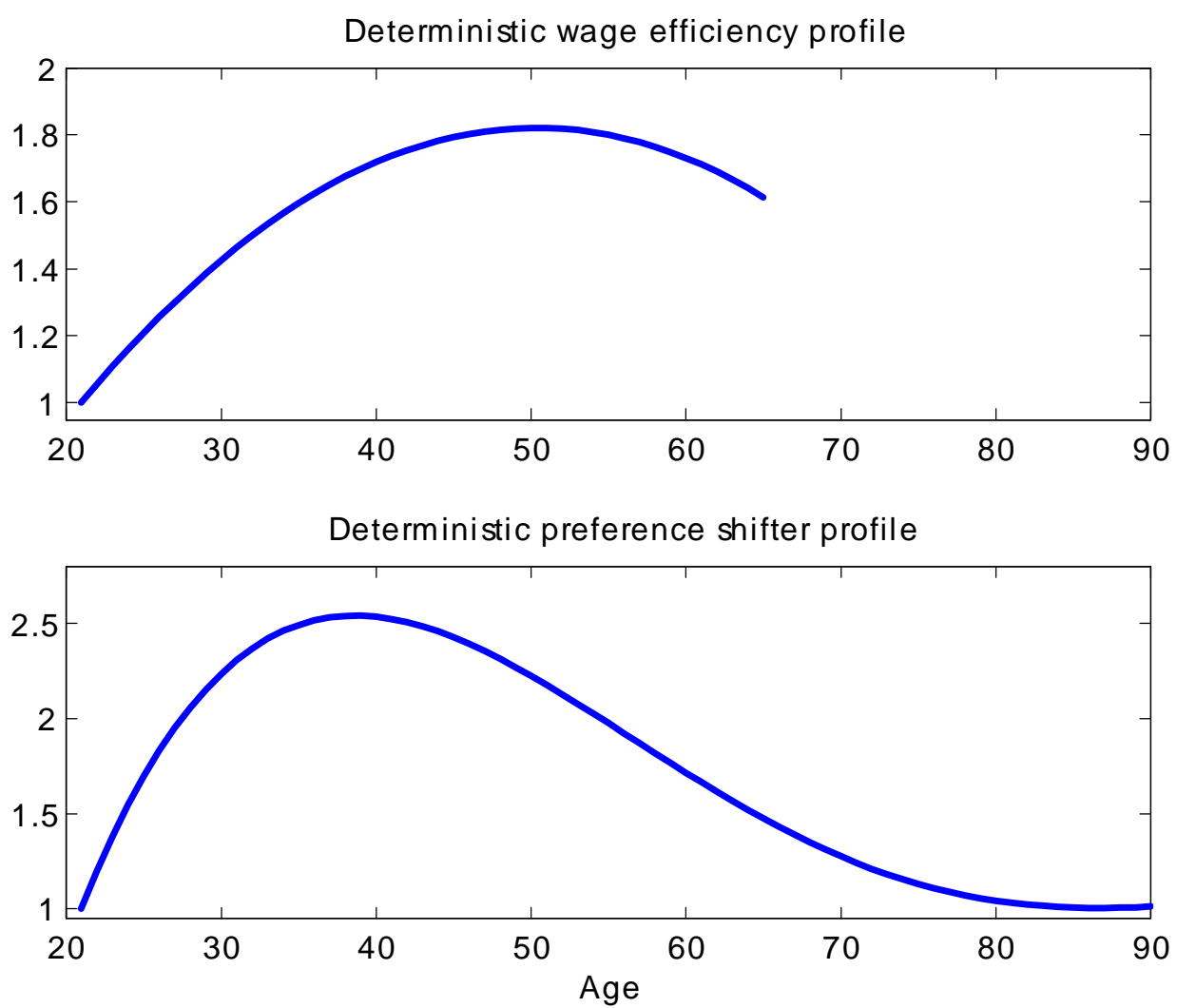
Figure 3: Homeowner's Housing Investment Decision as a Function of Initial House Size and Liquid Assets.

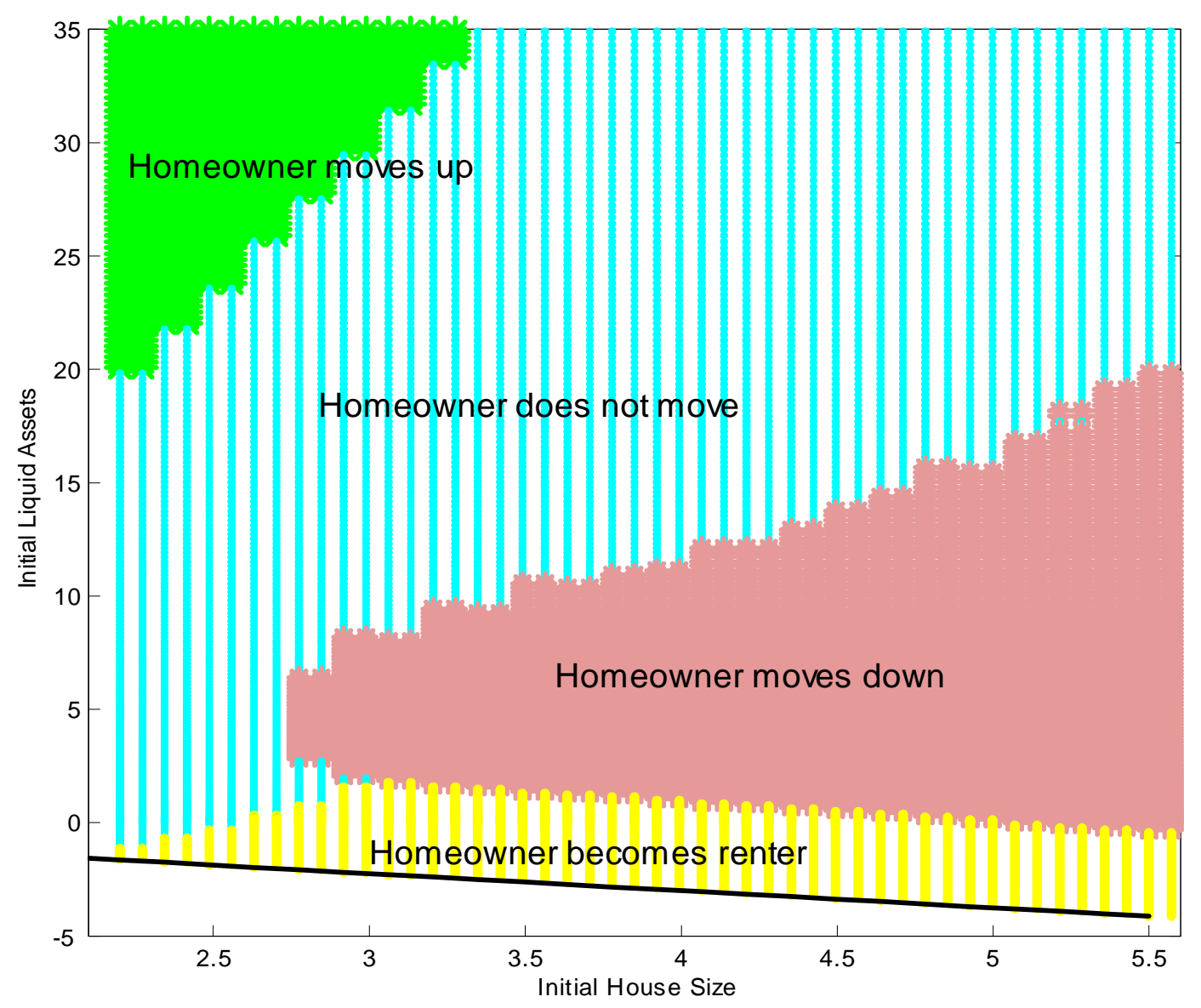

Note: The figure illustrates, for each combination of initial house and liquid assets, the homeowner's housing decision for next period. It is plotted for a patient agent who is 65 years old, when aggregate productivity and the average capital labor ratio are equal to their average value. 
Figure 4: A Typical Life-cycle Profile.
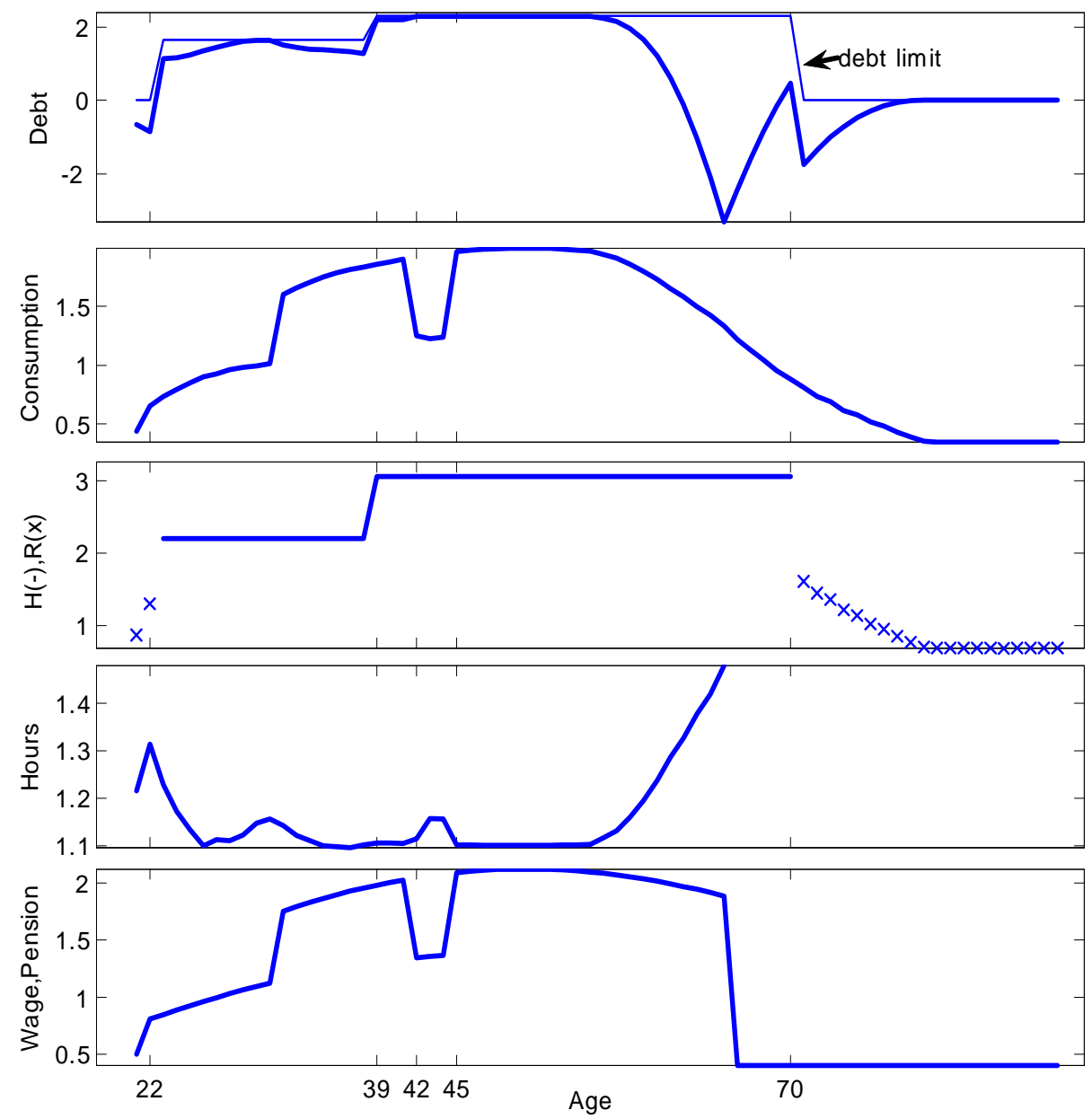

Note: This figure plots life-cycle choices of a randomly chosen impatient agent from birth (age 21) to death (age 90). In panel 1, the thin line denotes the maximum debt limit given the housing choice. In panel 3, the " $\mathrm{x}$ " symbol denotes the amount rented when the individual is renting, whereas the solid line denotes the amount owned when the individual owns a house. 
Figure 5: Comparison between Model (Baseline Calibration) and Data.
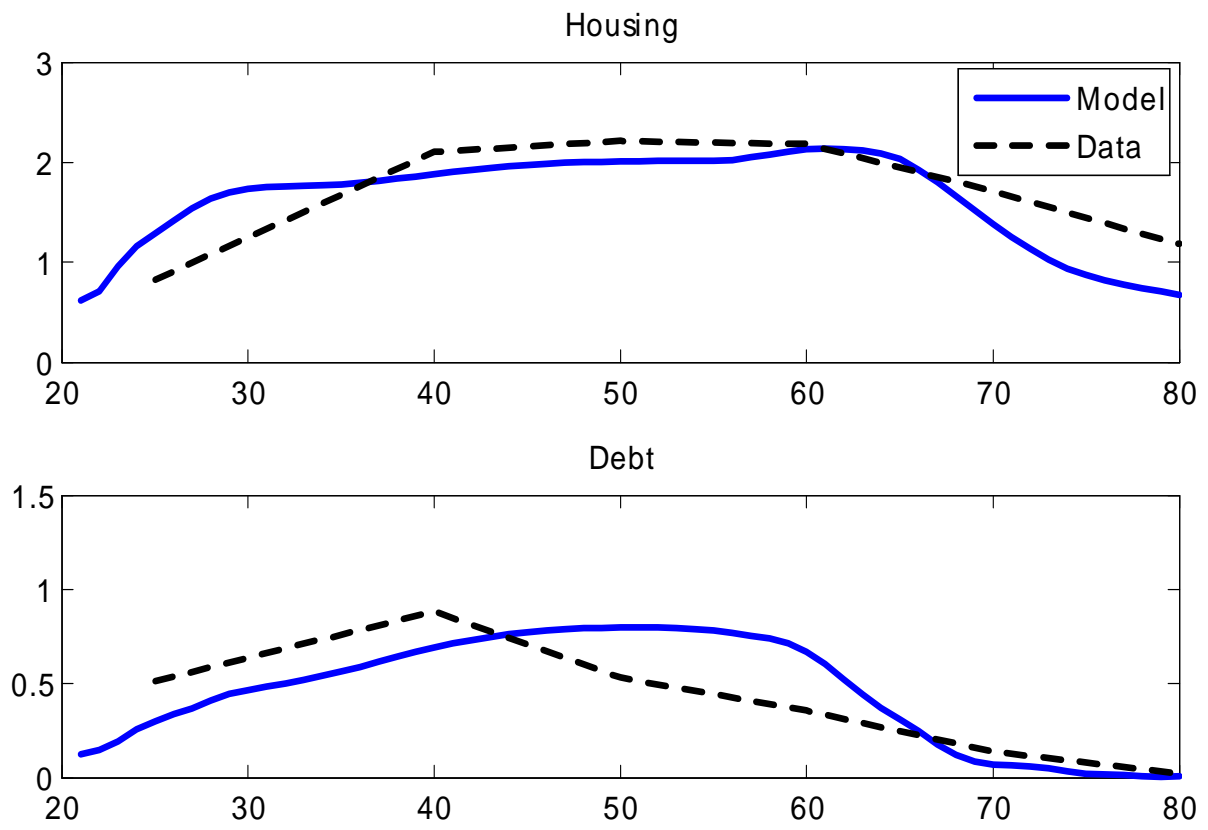

Home Ownership rate

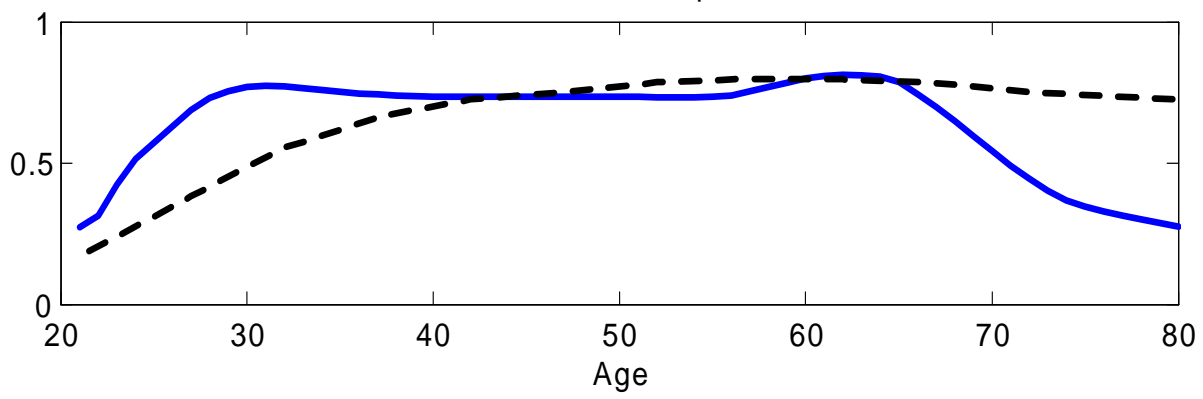

Note: The data come from the summary statistics of the 1983 Survey of Consumer Finances, as reported in Kennickell and Shack-Marquez (1992). For each age, the model variable is the product of the fraction of households in that age holding housing or debt, times the median holding of housing or debt. The data variable is constructed in the same way. 
Figure 6: Lorenz Curves for Total Wealth and Housing Wealth.

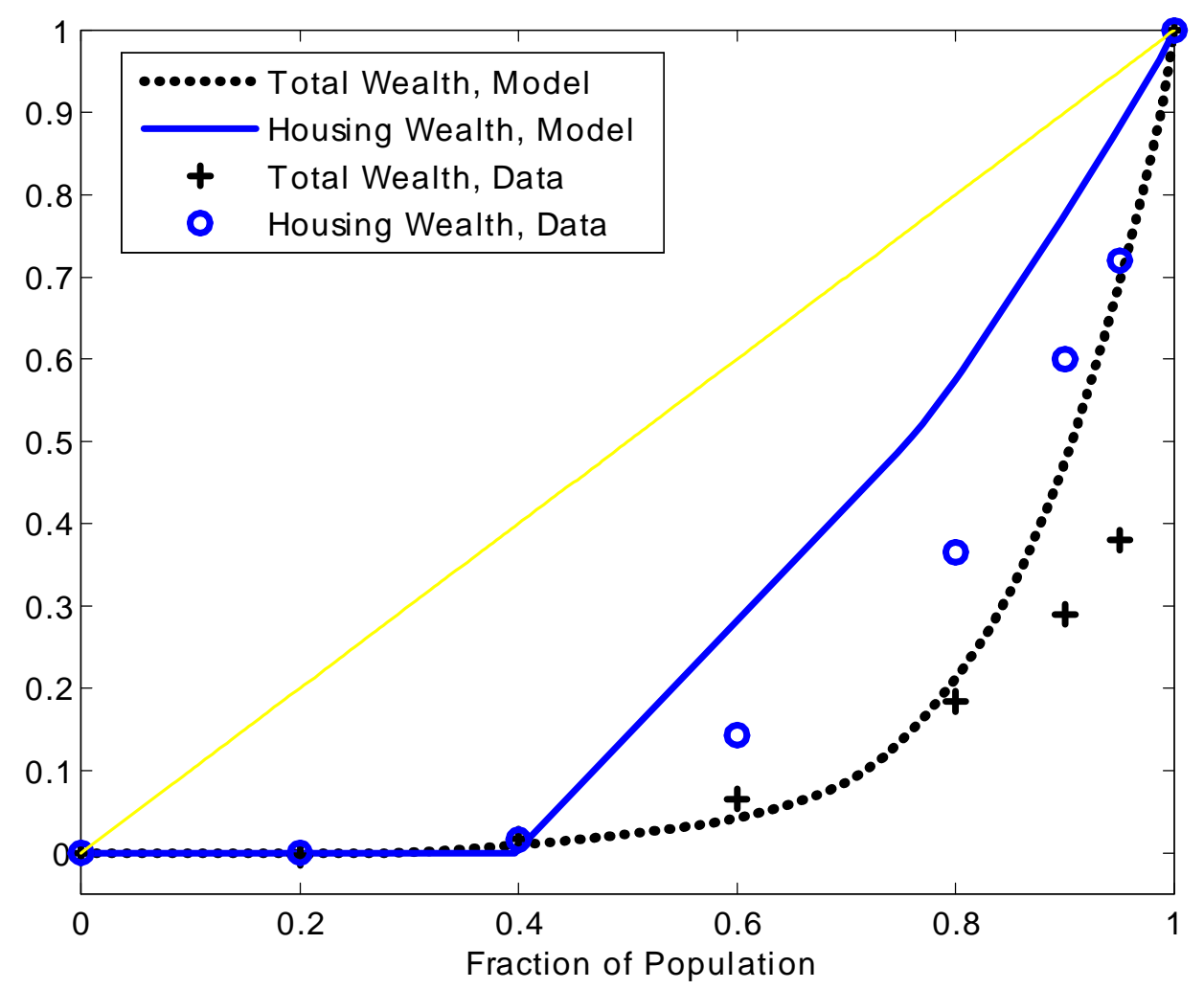

Note: The Lorenz curves for total wealth and housing wealth in the data are from Díaz and Luengo-Prado (2010) using data from 1998 Survey of Consumer Finances. 
Figure 7: Comparison between Early and Late Period: Debt, Hours and Housing by Age.
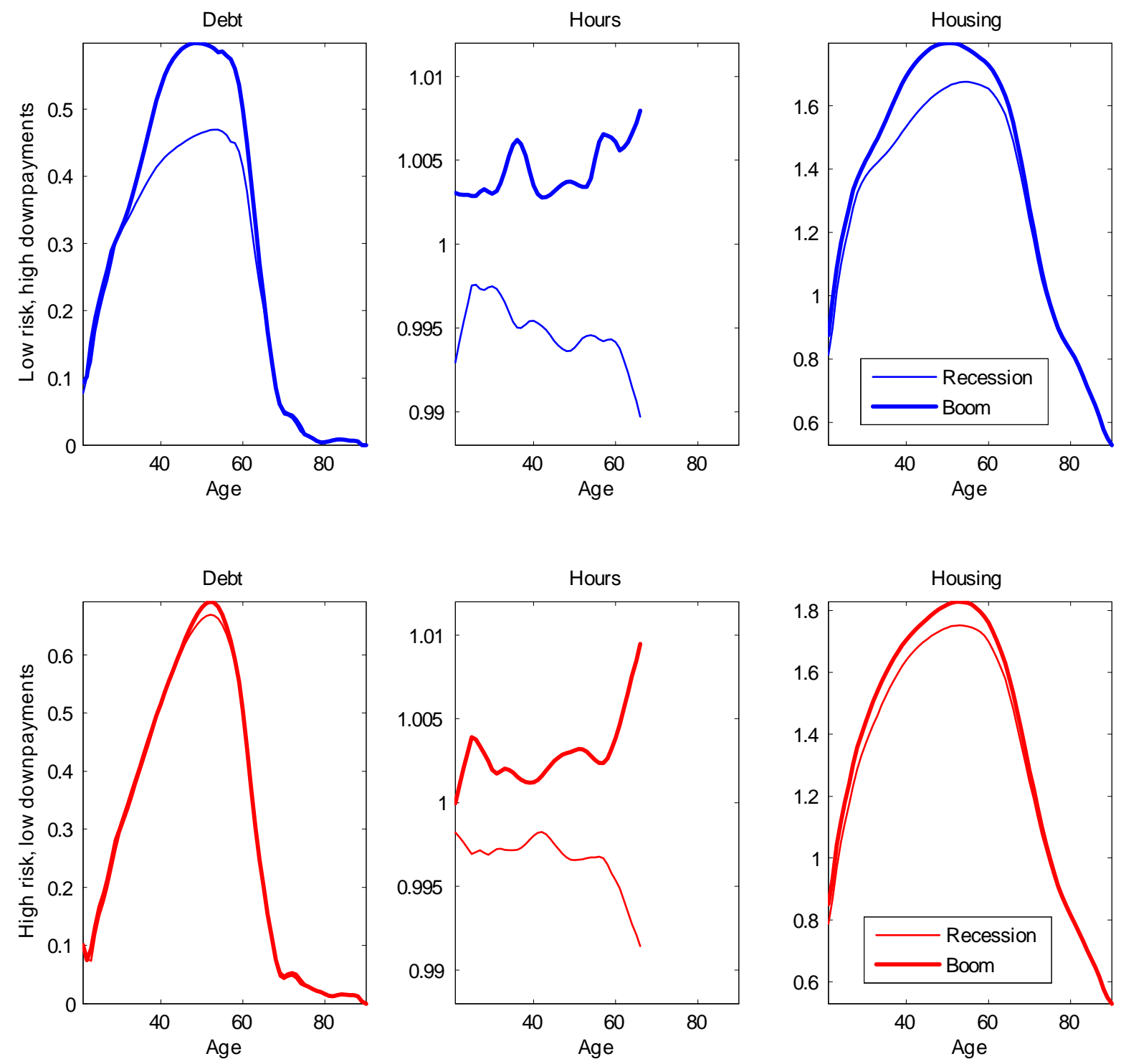

Note: The top panel plots model variables in the baseline calibration (low individual risk and high downpayment requirements), where housing, debt and hours worked are relatively more volatile (the difference between a boom and a recession is larger). The bottom panel plots the calibration with high individual risk and low downpayment requirements.

The thin/thick line shows the reading of each variable by age when the economy is in the lowest/highest aggregate state (recession/boom). Housing and Debt are expressed as a ratio of average GDP. Hours are normalized in each age by their age average. 
Figure 8: Impulse Responses to a Positive Technology Shock: Early and Late Period Calibration.
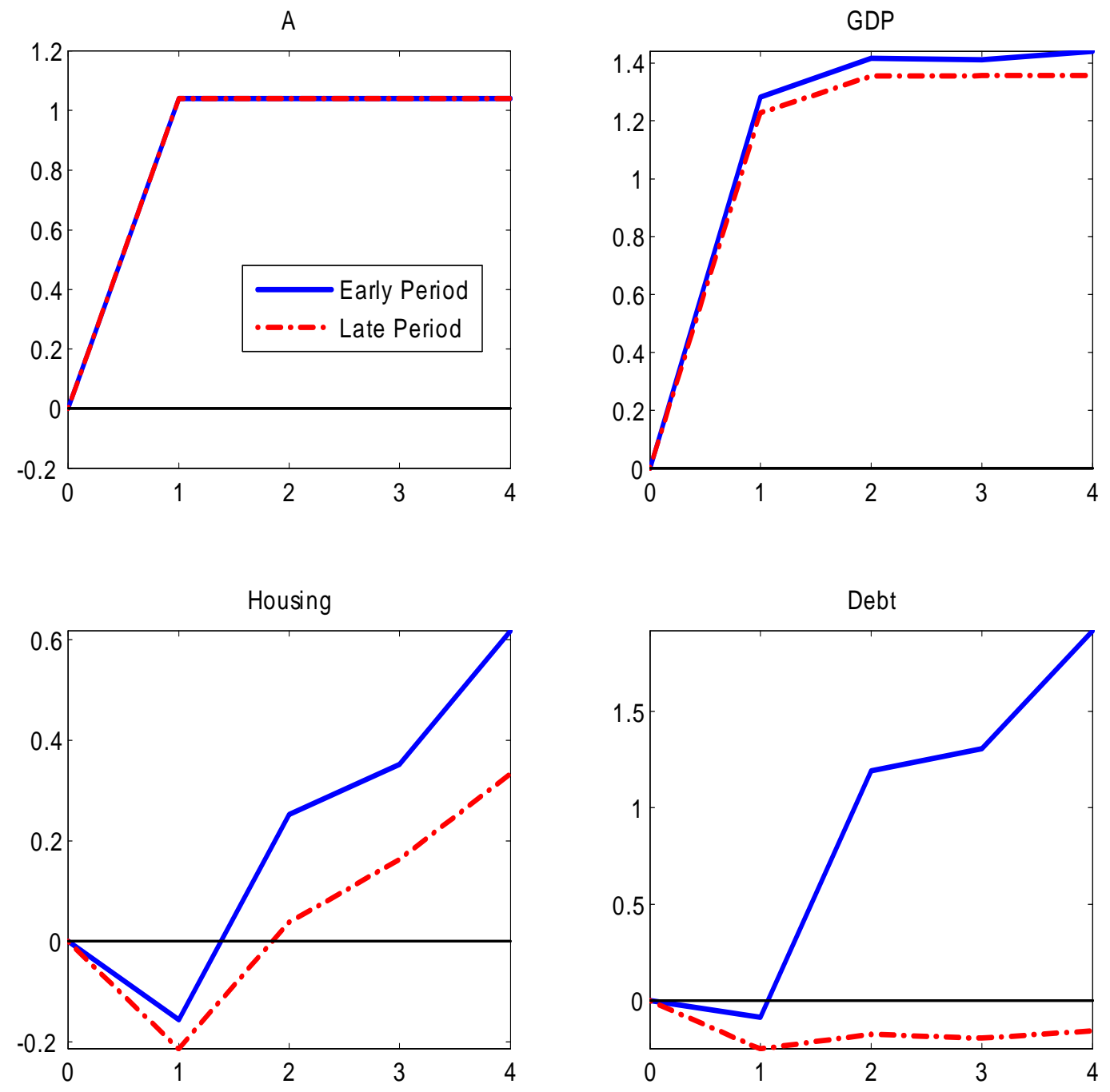

Note: Model dynamics following an exogenous switch in aggregate productivity $A$ (in period zero) from the median state to next higher value (a 1 percent increase) lasting four periods. Each variable is displayed in percent deviation from the unshocked path. 
Figure 9: Impulse Responses to Positive and Negative Technology Shocks: Comparison between the Early and Late Period Calibration, Model with Cyclical Loan-to-Value Ratios and Interest Rate Premia.
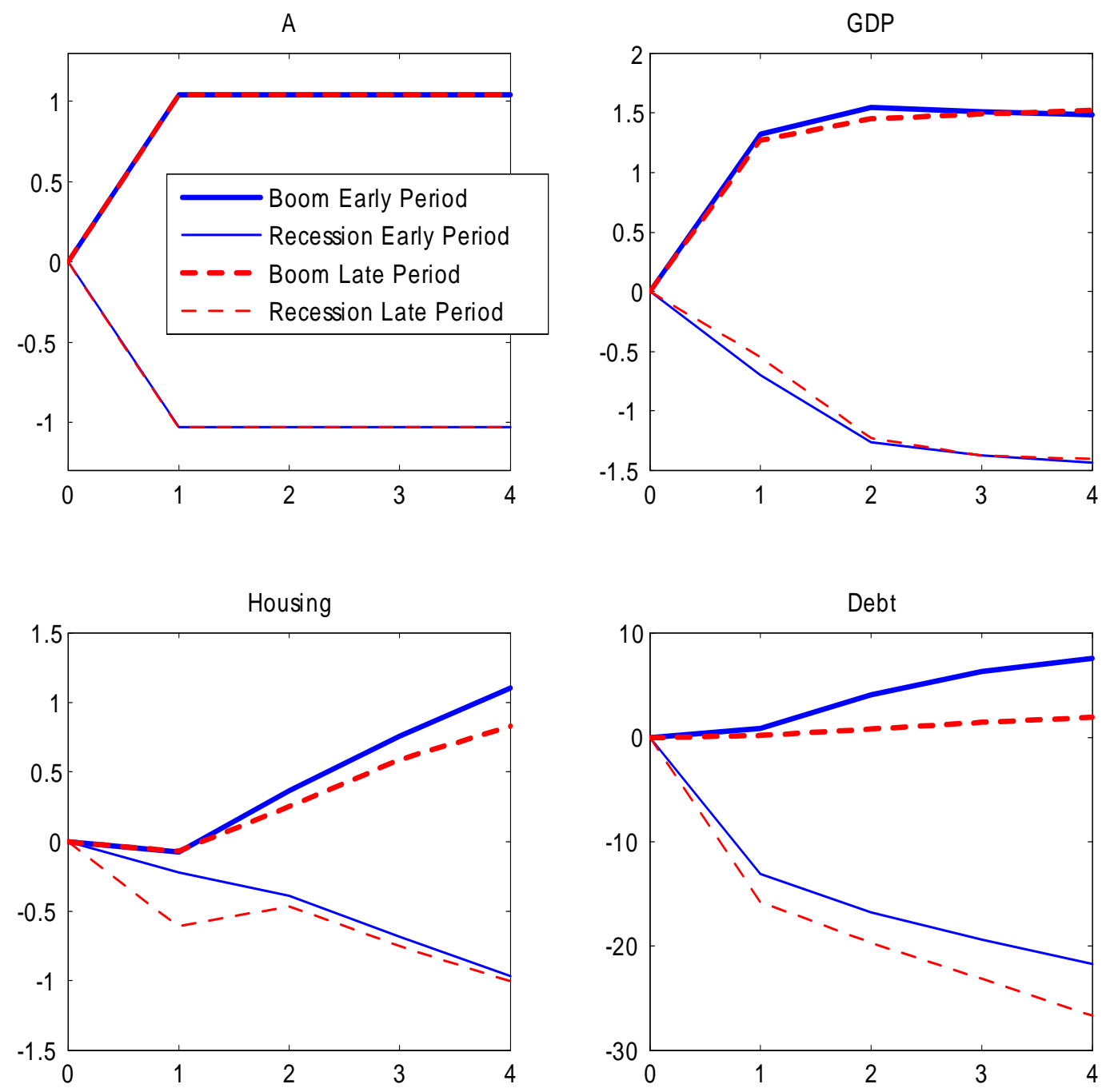

Note: Model dynamics following an exogenous switch in productivity $A$ in period zero. The thick lines plot a 1 percent increase in productivity that does not change financial conditions in the early (solid lines) and late (dashed lines) period calibration. The thin lines plot a 1 percent decrease in productivity together with a worsening in financial conditions. Each variable is displayed in percentage deviation from the unshocked path. 